\title{
Certification or Cash Prize: The Heterogeneous Effect of Venture Competitions
}

\author{
Gaétan de Rassenfosse ${ }^{\mathrm{a}}$ and Matthias van den Heuvel*a \\ ${ }^{\mathrm{a} C o l l e g e ~ o f ~ M a n a g e m e n t ~ o f ~ T e c h n o l o g y, ~ E c o l e ~ p o l y t e c h n i q u e ~ f e ́ d e ́ r a l e ~ d e ~ L a u s a n n e, ~ L a u s a n n e, ~ S w i t z e r l a n d ~}$
}

January 2021

\begin{abstract}
Venture competitions usually reward winners with a certification of their startup's quality and a cash prize. We model and estimate the impact of these rewards on startup performances using original data on about 1000 startups that have participated in a highly-regarded venture competition. We find that winning in the competition improves startups' performances on average. However, it does not affect all technology types equally. Startups in sectors where quality can be more objectively assessed enjoy a long-term benefit from the certification's effect. By contrast, startups with low running costs and whose quality is harder to evaluate only benefit temporarily from having received a cash prize, with no long-term effect. We also show that the competition's certification provides valuable information to both entrepreneurs and outside investors. This information accelerates the termination of low-quality startups and improves external funding opportunities for high-quality startups. Our results highlight sector-specific heterogeneity in startups early-stage support needs, which bears implications for the design of entrepreneurial programs.
\end{abstract}

JEL codes: D22, D80, G24, M13, 031

Keywords: entrepreneurial finance, venture competition, venture capital, certification, expert evaluation

*Email: matthias.vandenheuvel@epfl.ch. This project is supported by the Swiss National Science Foundation (SNSF) within the framework of the National Research Programme "Sustainable Economy: resourcefriendly, future-oriented, innovative" (NRP 73, Grant-No 407340-172395). We thank Sabrina Howell, Bruno Cassiman, Gary Dushnitsky, Henry Sauermann, Tom Åstebro and the participants at the 2019 SEI Doctoral Consortium for valuable comments. Finally, we thank Venture Kick, and in particular Patrick Biro, for having provided access to the data. 


\section{Introduction}

Venture competitions, events in which startups compete to receive money, mentoring or recognition, have become a key actor of the startup ecosystem. According to Howell (2019), about 15 percent of U.S. startups that secured their first seed or series A financing between 2009 and 2016 have won such a competition. Changes in the investment strategy of venture capitalists (VCs) are reportedly behind the rise of venture competitions. Faced with falling costs of starting a venture, investors have increasingly adopted a "spray and pray" investment approach (Ewens et al., 2018). VCs now provide more limited funding and governance to a greater number of startups - that they are more likely to abandon.

In this changing environment, venture competitions provide a welcome support to early-stage startups. First, they usually supply capital to the winning startups at a stage where acquiring financing is challenging, thereby mitigating potential financial constraints. Second, they often offer some form of mentoring or networking, presenting fledgling entrepreneurs with opportunities to improve their organization. Finally, winning a venture competition can act as certification of startup quality, providing valuable information about a startup's probability of success to both founders and investors. However, while winning startups predictably perform better after the competition on average than non-winning startups, there is no consensus on the exact nature of the causal effect of venture competitions on venture performances.

Research on venture competitions is still in its infancy. Scholars have proposed different reasons as to precisely why they are useful. McKenzie (2017) uncovers a cash prize effect, whereas Howell (2019) proposes a certification effect. By documenting the first order effects of venture competitions on startup performance, these papers help answer broad economic questions about the frictions facing young firms. The present paper provides a more nuanced understanding of the effect of venture competitions by showing that earlier findings are context-dependent. Specifically, it provides evidence that the credibility of the signal of winning the competition as well as the prize effect vary by technology type.

We start by developing a model of venture competitions' impact on participating startups. Our model yields two main testable predictions. The first is that in a welldeveloped financial system, venture competitions are useful mainly because they provide an informative certification of quality and not because they offer a cash prize. The sec- 
ond prediction is that venture competitions have a heterogeneous effect on participating startups depending on their technology. Certification is more valuable to startups in sectors where screening is more objective whereas the cash prize effect is concentrated on startups with low running costs.

To test these predictions, we have obtained original data on 987 startups that participated in Venture Kick, the leading Swiss venture competition, in the period 2008-2017. Switzerland has a vibrant entrepreneurial scene, it ranks fourth in the OECD in terms of the amount of venture capital investments per capita. The competition is organized in three eliminatory stages and provides up to $\$ 130,000$ to winning startups. This set-up is ideal for our purposes as we exploit the multi-stage nature of the competition to tease out the certification and the cash prize effects. Because winning the first stage is very often a startup's first certification of quality but comes with barely any financing, we argue that it primarily captures the certification effect. By contrast, winning the last stage comes with a large cash prize and, therefore, predominantly captures the cash prize effect. Our main identification strategy exploits detailed data on grades given by the judges, which we use to control for differences in startup quality.

We find that winning the first stage of the competition increases survival rates two years after the competition by 22 percentage points. It also increases the probability of securing subsequent external financing by 14 percentage points. These two findings provide evidence of a certification effect. Further, in line with our model's first prediction, we observe that winning the second or third stages has no causal impact on startups' future survival rates or funding outcomes, which casts doubt on the presence of a cash prize effect. Then, as hypothesized, we find that Venture Kick's effect depends on the startups' technology. The certification effect is particularly strong among startups whose quality can be more objectively assessed by the competition's judges, which we proxy with the science-based startups (including medtech, biotech, and cleantech) in our sample. By contrast, the cash prize effect exclusively benefits startups with relatively low running costs and whose quality is harder to assess, proxied by internet, mobile \& software (ICT) startups. Receiving a prize improves the survival rates of ICT startups in the short term with no long-term impact on their performances.

Our analysis suggests that venture competitions' effect depends on the quality of judges' screening and startups' running costs. We observe that judges are better at identifying the best science startups than they are at picking out the best ICT ventures, presumably because the technological and market viability of science-based ventures can be assessed more objectively (Scott et al., 2020). The certification provided by venture 
competitions is, therefore, too noisy a signal of quality for ICT startups. However, these startups do still benefit from winning the competition. Because ICT startups have lower running costs than science-based startups, the cash prize significantly extends their runway. Our results are robust to alternative specifications and identification strategies, including a sharp regression design, a propensity score matching and a regression model that allows grades to be observed with some level of imprecision.

Another notable finding is that the certification effect seems to work in two ways. First, it acts as a type-revelation mechanism. It provides both winning and losing entrepreneurs with information on their startup's quality that can help them adjust their probability of success. Like Yu (2019), we find evidence that losing startups shut down earlier than they would have otherwise. Second, when the judges' evaluation of startups' quality is expected to be more reliable, as in the case of science-based startups, certification can reduce the information asymmetry between entrepreneurs and investors. As a result, winning startups improve their chances of securing external financing after the competition.

The paper contributes to the nascent literature on venture competitions. Our findings in Switzerland and Howell's in the United States indicate that most early-stage startups in advanced economics with well-functioning financial systems may not necessarily benefit significantly from receiving a cash prize of around $\$ 100$ '000. Only those startups with low running costs and whose quality is harder to certify may benefit from this source of financing. However, venture competitions can serve as a useful complement to venture capital (VC) by providing valuable information on the startup's quality to both entrepreneurs and outside investors. This information accelerates the termination of lowquality startups and improves external funding opportunities for high-quality startups. For this certification to be useful, however, experts' evaluation needs to be accurate. This explains why inherently harder to evaluate startups benefit less than science-based startups from Venture Kick's certification effect.

The paper is organized as follows. The next section provides background information on venture competitions. Section 3 presents our model and its theoretical predictions. Section 4 presents Venture Kick, discusses the data and provides descriptive statistics. Section 5 details our preferred empirical strategy. Sections 6 and 7 test the two main predictions of our model, investigating Venture Kick's average and industry-specific impact. Section 8 concludes. 


\section{Background}

VCs have long been established as a crucial source of early-stage financing for startups (Hellmann and Puri, 2002). More than simple suppliers of financial resources, they typically improve the outcomes of the startups they invest in by providing governance, monitoring and mentoring (Kaplan and Lerner, 2010). However, the last decade has seen a sharp decrease in the cost of starting a new high-technology startup or of experimenting new ideas. ${ }^{1}$ This decrease in costs has sparked change both in the way VCs invest and the type of investors that are now able to provide support to early-stage ventures (Nanda and Rhodes-Kropf, 2016; Ewens et al., 2018). VCs have increasingly adopted a "spray and pray" investment approach (Ewens et al., 2018), whereby they make a large number of small investments in early-stage ventures with limited due diligence and governance in the hope that a handful of these ventures will hit a home run. An increased number of startups are now financed but they are also then more likely to be abandoned if their potential is not realized. This reduction in VC firms' governance and the fall in the cost of starting a business help explain the emergence of new early-stage financial intermediaries such as venture competitions, accelerators/incubators, angel networks or crowdfunding that provide scalable, lower-cost forms of mentorship (Ewens et al., 2018). In the past decade as these new financial intermediaries have grown in importance, a literature has emerged to study this new phenomenon.

The rise in accelerators and incubators and their efficiency have been documented by Hochberg and Fehder (2014), Hochberg (2016) and Yu (2019). Angel investors have also been studied in recent years with Kerr et al. (2011) and Lerner et al. (2018) showing that the participation of angel investors in early-stage ventures increases their survival, employment and follow-on financing. Finally, Mollick (2014) and Hildebrand et al. (2017) analyze the crowdfunding phenomenon spearheaded by platforms like Kickstarter.

Venture competitions have so far received less academic attention (McKenzie, 2017; Howell, 2019). Yet, they are an important actor in the startup ecosystem. According to Howell (2019), 14.5 percent of the startups reported on the American data platform CB Insights that secured their first seed or series A financing between 2009 and 2016 won a venture competition. These competitions are events in which a number of startups compete through one or more stages. Their founders pitch their technologies and business

\footnotetext{
${ }^{1}$ One event that is credited with having sharply reduced the cost of starting a startup is the introduction of Amazon's Web Services (AWS) in early 2006, a cloud computing service (Ewens et al., 2018).
} 
models to a panel of judges in the hope of receiving funding, mentoring or certification of quality. For the most part the literature has found that venture competitions are useful to startups because of either their certification or their cash prize.

Regarding certification, the competition's judges provide useful information about the value and potential of participating startups (Scott et al., 2020). This is important because information acquisition is crucial in the investment decision of early-stage investors (Bernstein et al., 2017). Indeed, Gompers et al. (2020) find that between deal sourcing, deal selection, and post-investment value added it is selecting the right startup that is the most important determinant of VCs success. Moreover, information asymmetry between investors and entrepreneurs has long been identified as a problem that hinders investment in startups (Amit et al., 1990), and this problem might have become even more acute today. Indeed, the fall in costs has lowered the barriers to entry, making it harder for VCs and other early-stage investors to determine each startup's quality (Ewens et al., 2018). Venture competitions' certification of quality can, therefore, reduce the information asymmetry problem between entrepreneurs and early-stage investors. These competitions also provide entrepreneurs with valuable information about their startup's probability of success, guiding their decision to proceed or stop further development efforts. Asstebro and Gerchak (2001) find that the advice to proceed or not with a venture provided by Canada's Inventor's Assessment Program generated higher benefits for society than the costs of running it. Evidence of this certification effect is put forth by Howell (2019). The author finds that winning a venture competition seems to primarily serve a certification function, signalling quality to the market and reducing search frictions between VCs and entrepreneurs. Yu (2019) finds that accelerators provide informative signals to founders about their probability of success. This helps resolve uncertainty around company quality sooner, allowing founders to make funding and exit decisions accordingly.

Turning now to financing, venture competitions have the potential to alleviate a startup's financial constraints. There is a lot of evidence that liquidity constraints have an impact on the viability of startups, starting with (Holtz-Eakin et al., 1994), or that the growth of most firms is constrained by internal finance (Carpenter and Petersen, 2002). Moreover, Clementi and Hopenhayn (2006) have shown that borrowing constraints have important implications for firm growth and survival. By providing a cash prize, venture competitions can typically alleviate some of the winning startups' financial constraints. This effect is highlighted by McKenzie (2017). Studying a competition in Nigeria that awarded almost $\$ 50,000$ to its winners, the author finds that winning is helpful mainly 
because the prize alleviates financial constraints. Smith and Viceisza (2018), looking at the Shark Tank competition, also find that it is the financing that ultimately matters and not the signal of quality that winning the show provides. In the context of the government-sponsored SBIR grant program, Howell (2017) finds that it is the money rather than the certification that is likely to explain the grant's effect.

In order to reconcile these different results, we propose that variations in the competitions' set-ups need to be considered. Everything else equal, it seems logical that a cash prize will be relatively more useful in Nigeria (McKenzie, 2017) than in the United States (Howell, 2019), where startups have access to numerous alternative sources of financing. Moreover, the size of the cash prize certainly matters. In the SBIR and Shark Tank's case, the financing provided is much larger than in typical venture competitions, which may help explain why the authors observe a financing effect (Smith and Viceisza, 2018; Howell, 2017). ${ }^{2}$ This discussion suggests that we need a more fine grained understanding of the effect venture competitions. The next section proposes a model that considers contexts under which the certification and the financing effects will matter to different degrees.

\section{Theory}

\subsection{The Model}

In order to better understand how venture competitions impact participating startups, we develop a model from which we draw several testable predictions. We consider three types of agents: entrepreneurs, investors and venture competitions. Entrepreneurs each own a startup $i$ that can be of one of $k$ technologies assigned randomly by nature at time $t=0$. To operate, startups pay a fixed cost $C(k)$ each period. Entrepreneurs have to decide at the beginning of each period $t$ whether to continue their activity $\left(y_{i, t}\right)$.

The second agents, investors, own capital and have to decide once whether to invest $\left(g_{i}\right)$ in a given startup $i$. These decisions are made with imperfect information, because neither entrepreneurs nor investors know the true quality $\theta_{i}$ of startup $i$. This quality is assigned by nature at $t=0$ and will influence a startup's future revenues $R\left(\theta_{i}, t\right)$. Revenues also depend on $t$ because they typically increase as a startup transitions from the early stage to its growth stage. However, these future revenues, $R_{i, t}$, are unknown

\footnotetext{
${ }^{2}$ In the SBIR grant program, winners can obtain up to $\$ 1.15$ million while 57 percent of the Shark Tank's contestants receive funding of an average amount of around $\$ 145,000$.
} 
because $\theta_{i}$ is unobserved. Instead, entrepreneurs and investors observe imperfect signals of startup quality, which they use to predict startup quality $\hat{\theta}\left(S_{i, k}, Z_{i, t}\right)$. $Z_{i, t}$ is any information about a startup's true quality (e.g., background of the entrepreneurial team) and $S_{i, k}$ is an external quality signal such as the one provided by venture competitions. This predicted quality is then used to estimate expected revenues, $\widehat{R}_{i, t}$. Unlike $\theta_{i}$, which is fixed, $\widehat{\theta}_{i, t}$ can evolve as decision-makers receive more information.

The third agents, venture competitions, provide participating startups with the following two things. First, they offer a certification of quality $S_{i, k}$ that provides additional information to both entrepreneurs and investors, allowing them to update $\widehat{\theta}_{i, t}$. This certification can be either positive (i.e., $S_{i, k}=1$ ) or negative (i.e., $S_{i, k}=-1$ ). Second, the competition gives a financial reward Prize $e_{i, t}$ to its winners, whose use is strictly limited to covering the costs of the startup and which is lost if the company stops its activity. ${ }^{3}$

To simplify our infinite-horizon problem formulation, we assume without loss of generality that our agents are fully patient - the discount rate $\beta$ is thus 1 - and we set the risk-free rate at 0 . The timing of the model is as follows. In period $t=0$, nature assigns a quality $\theta_{i}$ and a technology $k$ to each startup. We assume that the entrepreneurs start with a negligible amount of capital of their own. In period $t=1$, entrepreneurs receive information about the true quality of their startup via $Z_{i, t}$. They then adjust the estimated quality of their startup $\widehat{\theta}_{i, t}$ and, based on this estimate, make their decision about whether to pursue the business. At the beginning of period $t=2$, some of the startups still alive are randomly selected to participate in a venture competition. ${ }^{4}$ Then from period $t=2$ onward, entrepreneurs and investors use both $Z_{i, t}$ and $S_{i, k}$ to estimate $\widehat{\theta}_{i, t}$ and make their decisions.

\footnotetext{
${ }^{3}$ As far as we can see, two more aspects of venture competitions could benefit participating startups. First, participating in a venture competition usually offers valuable mentoring and networking opportunities. It has long been established that one of the most important contributions of early-stage investors is to mentor budding entrepreneurs (Timmons and Bygrave, 1986). Second, participating in a venture competition is a useful learning process. Tournament theory posits that competitions can be useful because they provide an incentive for participants to put some effort into improving their startup (Connelly et al., 2014). Moreover, competitions provide experience that can improve entrepreneurs' performances, in a learning-by-doing framework (Arrow, 1971; Minniti and Bygrave, 2001). The literature offers no indication that these two aspects are major drivers of startup's future success. For this reason and to keep our model simple, we purposefully neglect them in our model.

${ }^{4}$ As we are not interested in the decision to participate in a venture competition, we treat participation as random. Note that the majority of startups will survive in the first periods when $Z_{i, t}$ is small in absolute value - they have little information about their true quality. This overconfidence of entrepreneurs is well-documented in the literature (Koellinger et al., 2007).
} 


\subsubsection{The decision of the entrepreneur}

The entrepreneur chooses each period whether or not to continue with their activity - if they shut down in period $t$ then $y_{i, t+j}=0 \forall j \in[0, \infty]$-based on the expected Net Present Value (NPV) of the venture at time $t$. The main determinant of the NPV is the startup's estimated quality at time $t, \widehat{\theta}_{i, t}$. In order to consider the fact that a startup might fail and cease to exist, future revenues are weighted by the estimated probability of it being alive $n$ periods in the future, $\widehat{y}_{i, t+n}$. Crucial to these quality assessments, $Z_{i, t}$ is a function of its past value and a stochastic variable $\gamma_{i, t}$ that depends on $\theta_{i}$. We allow the certification $S_{i}$ to have a varying impact on $\widehat{\theta}_{i, t}$ depending on how credible and trusted the certification is, which in turn is a function of startup $i$ 's technology $k$. Finally, as periods pass, startups accumulate their own Capital $_{i, t}$ which is the sum of past profits but will never encompass the non-appropriable cash prize. Consequently, Capital $_{i, t}$ can be negative and will never exceed the sum of past revenues. The different variables in the model are defined as follows:

$$
\begin{aligned}
N P V_{i, t} & =\sum_{n=0}^{\infty} \widehat{y}_{i, t+n}\left(\widehat{R}\left(\widehat{\theta}_{i, t}, t+n\right)-C(k)\right) \\
\widehat{\theta}_{i, t} & =f\left(h_{k}\left(S_{i}\right), Z_{i, t}\right) \\
\widehat{y}_{i, t+n} & =f\left(\widehat{\theta}_{i, t}, t+n\right) \\
Z_{i, t} & =Z_{i, t-1}+\gamma_{t}\left(\theta_{i}\right) \\
\operatorname{Prize}_{i, t} & =\max \left(\operatorname{Prize}_{i, t-1}-C(k), 0\right) \\
\text { Capital }_{i, t} & =\sum_{t=1}^{t-1} R_{i, t}-\max \left((t-1) C(k)-\operatorname{Prize}_{i, 2}, 0\right)
\end{aligned}
$$

At the beginning of each period $t$, the entrepreneur can be in one of four situations depicted in the decision tree below. To begin with, if entrepreneur $i$ estimates that their startup's NPV is positive they have two options. If the startup has enough cash available to cover its running cost during period $t$ it will choose $y_{i, t}=1$. However, if the startup is not able to pay for its costs during period $t$ it will only pursue its activity if it can secure some funding and will be forced to shut down otherwise. Now if an entrepreneur estimates that their project is not viable in the long term (i.e. $N P V<0$ ) they have two options. They will choose $y_{i, t}=1$ if they expect their revenue in period $t$ and what remains, if anything, of the prize to cover the cost of running the business during period $t$. Pursuing the venture one more period could allow them to increase the entrepreneur's own capital - the prize is lost if the startup stops its activity - or receive new information, 
$Z_{i, t+1}$, that could make the NPV positive. Finally, they will choose $y_{i, t}=0$ if the prize and the expected revenues do not cover the costs, taking with them whatever capital remains rather than continuing to run an unprofitable business.

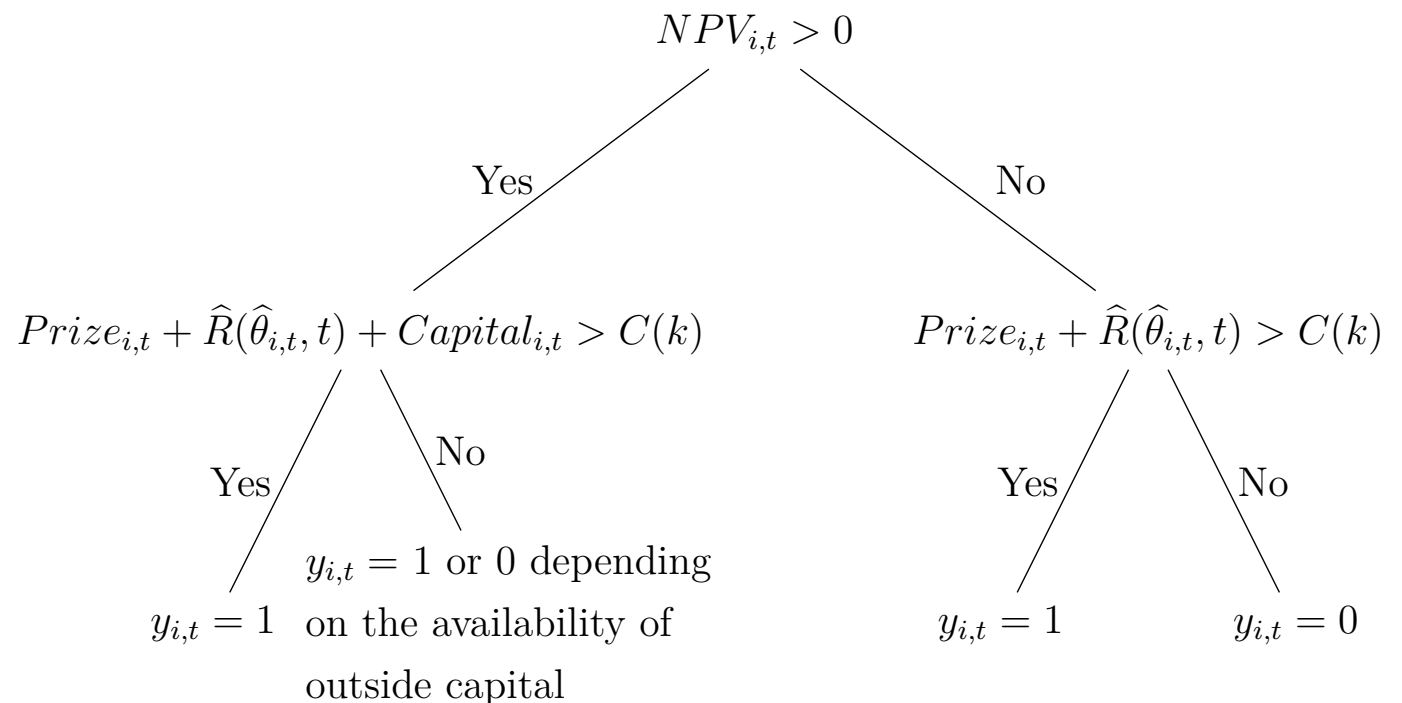

Our model implies that the prize's impact on startup survival will depend on the level of development of the local financial system. If sources of early-stage financing are abundant, the Prize will only be helpful in the short term to startups with a negative NPV. However, in a setting with very limited sources of outside funding, the Prize could take on another crucial role. It could allow some promising but cash-strapped startups (i.e. $N P V>0$ ) to survive in their early-stages.

\subsubsection{The decision of the investor}

The investor chooses once whether to invest in a given startup $\left(g_{i, t}=1\right.$ if they decide to invest). Investing means providing $I$ in exchange for a return $r$ on future profits $N P V_{i, t}$. The Prize does not enter the equation because it cannot be appropriated by the investors and it does not impact the NPV. The investor's decision is simpler than the entrepreneur's; invest if they expects their investment to yield more than its cost and do not invest otherwise.

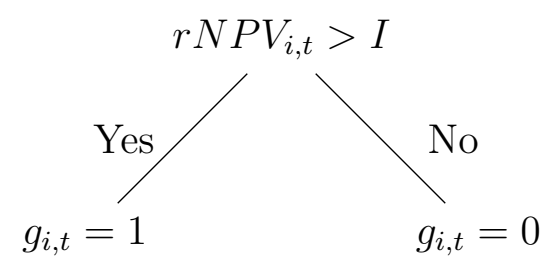




\subsection{Predictions drawn from our model}

Before drawing some predictions from our model, we need to make explicit three assumptions on which we rely. First, we assume that the certification is an informative signal of quality, that is, $\operatorname{corr}\left(S_{i, k}, \theta_{i}\right)>0$. For certification to be informative, judges need to be able to accurately assess startups' quality. This first assumption is supported by the fact that, as we show in Section 5.1, judges' grades in our data are highly predictive of startups' future success. Second, we assume that the judges' ability to identify high-quality startups differs by technology type. Both our data (see Figure 2) and the literature back this assumption. Indeed, Scott et al. (2020) find that experts can effectively differentiate among early-stage ventures on grounds of quality in the hardware, energy, life sciences, and medical devices sectors but cannot do so for ventures in the consumer products, consumer web and mobile, and enterprise software sectors. A possible explanation for this difference is that the success of science-based startups depends on elements that are more 'objective' compared to consumers products or ICT startup (i.e., hard evidence of a technological advance). Under this assumption, the competition's certification provides more information on a life science venture than it does on an ICT venture, which implies that $\operatorname{corr}\left(S_{i, k=\text { life_sciences }}, \theta_{i}\right)>\operatorname{corr}\left(S_{i, k=I C T}, \theta_{i}\right)$. Finally, as we are interested in the impact of venture competitions in advanced economies, we assume that the startups in our model evolve in a well-developed financial system. This implies that, if needed, startups can find external financing as long as they are of sufficiently high quality.

\section{Proposition 1: Venture competitions are useful, mainly because they provide an informative certification of quality.}

Assuming that the certification is informative (i.e., $\operatorname{corr}\left(S_{i, k}, \theta_{i}\right)>0$ ), it improves agents' decisions (i.e., $\frac{\partial y_{i, t}}{\partial S_{i, k}}, \frac{\partial g_{i, t}}{\partial S_{i, k}}>0$ ). $S_{i, k}$ is useful because it affects how entrepreneurs and investors estimate the startup's probability of success $\left(\hat{\theta}_{i, t}\right)$. On the one hand, startups that lose in the competition (i.e. $S_{i, k}$ goes down) see their estimated NPV go down. The fall in NPV causes them to close down earlier and makes it harder for them to secure funding, thus reducing potential waste of resources on low-quality projects. On the other hand, winning startups now have a higher NPV, which leads them to survive for longer and secure more external funding. At the same time, the cash prize can, at best, only have a short term impact on entrepreneurs because, unlike certification, it does not affect the NPV of a venture. In a well-developed entrepreneurial financial system, promising startups will have the opportunity to secure external funding if they lack the liquidity 
to cover their costs. The cash prize might nonetheless allow a startup with negative NPV to survive a few more periods, allowing it to gather additional information about its true quality or increase its capital. The fact that startups in our sample operate in a mature financial system can explain why our prediction that cash prizes are not crucial to startups long-term success differs from McKenzie (2017)'s finding that cash prize are successful in alleviating the capital constraints of Nigerian startups. Finally, the cash prize should have no impact on the investors' decision because they will never be able to claim ownership of it and it does not increase the NPV.

Lemma 1.a: Entrepreneurs react more strongly to a negative certification than to a positive one.

In other words: $\frac{\partial y}{\partial S_{0 \rightarrow-1}}>\frac{\partial y}{\partial S_{0 \rightarrow 1}}$. This result comes from the fact that a startup alive at time $t=2$ when the competition occurs, must have estimated at time $t=1$ that its NPV was positive. This decision implies that $\hat{\theta}_{i, 1}$ or $f\left(S_{i, k}=0, Z_{i, 1}\right)$ was high enough to warrant pursuing the activity. Therefore, everything else being equal, the fact that $S_{i, k}$ goes from 0 to 1 should have little impact on winning startups' decision to pursue their activity. On the other hand, startups that lose in the competition receive the information that $S_{i, k}$ goes from 0 to -1 , which will decrease $\widehat{\theta}_{i, t}$ and, in turn, the NPV. The latter could fall below 0 for some losing startups, causing them to stop their activity.

Lemma 1.b: Marginal startups are most affected by certification.

In this context marginal startups are those that are very close to the threshold quality that warrants investing time and money in them. Lemma 1.b follows from the fact that it is the startups that just barely have a positive or negative NPV that will be most affected by the additional information provided by $S_{i, k}$. Those whose NPV is far above 0 because they estimate their $\widehat{\theta}_{i, t}$ to be high thanks to a high $Z_{i, t}$, will be less affected by a positive or negative $S_{i, k}$. The same reasoning applies to an investor's decision to invest in a startup. A positive certification will not impact the investors' decision to invest in startups they estimate to be obvious hits or duds. It might however be just the extra information needed to make a marginal investment worthwhile. 


\section{Proposition 2: Venture competitions have a heterogeneous effect on partici- pating startups, depending on their technology.}

Lemma 2.a: Certification is more useful to startups in sectors that experts' are adept at screening.

This result stems from the fact that a certification will only be useful if it provides trusted and accurate information. However as discussed in Section 3.2, the ability of judges to screen startups varies across technology types. We define the sectors where experts can objectively identify startups' quality as high_info and the sectors where experts struggle to do so as low_info. The certification provides more information about its true quality $\theta_{i}$ to a high_info startup than to an low_info one. The information is also more objective about high_info startups' potential and therefore harder to dismiss for both entrepreneurs and investors. Because of that, we argue that investors and entrepreneurs in the high_info sectors are more responsive to certification and significantly adjust their estimation of a startup's quality $\widehat{\theta}_{i, t}$ and, consequently, their decisions $y_{i, t}$ and $g_{i, t}$. In other words, because $\frac{\partial \theta_{i}}{\partial S_{i, k=h i g h \_ \text {info }}}>\frac{\partial \theta_{i}}{\partial S_{i, k=\text { low_info }}}$ we predict $\frac{\partial y_{i, t}}{\partial S_{i, k=h i g h \_ \text {info }}}>\frac{\partial y_{i, t}}{\partial S_{i, k=l o w \_ \text {info }}}$.

Lemma 2.b: The cash prize's effect is concentrated on startups with low running costs. This results follows from our prediction in Lemma 1.b that the cash prize's only role, in a well-developed financial system, is to allow less viable startups to survive a few more periods than they would have been able otherwise. Consequently the cash prize should only have a noticeable impact on startups in sectors with sufficiently low running costs. Startups that require large capital investments will not be able to pursue their activity on the back of the cash prize alone.

\section{Data}

\subsection{Setting}

Switzerland and Venture Kick, its leading venture competition, offer an ideal setting to study the impact of venture competitions. In order to asses the predictions of our model, we need the startups in our sample to be located in a thriving entrepreneurial environment with many active early-stage investors. Switzerland is such a place. According to the OECD's Entrepreneurship Financing Database, Switzerland is the fourth OECD country with the highest amount of venture capital investments per capita (af- 
ter the United States, Israel and Canada). ${ }^{5}$ Additionally, the venture competition we study needs to provide both certification and a cash prize in a way that allows us to estimate their impact separately. These rewards also need to have been provided in both a consistent and reliable manner throughout the years. Venture Kick satisfies all these criteria. Indeed, Venture Kick has maintained a very similar reward structure in terms of certification/publicity and cash prize during the entire period of our sample. Moreover, the judges have graded startups using the exact same guidelines and criteria since the start of the competition in 2007.

\subsection{The Venture Kick Competition}

Venture Kick is a Swiss venture competition based in Lausanne and Zurich. It has awarded more than $\$ 29$ million to 675 startups since its launch in 2007 (Venture Kick, 2019). Its aim is to increase the number of spin-offs at Swiss universities, accelerate the time-to-market and raise the attractiveness of these young companies to professional investors. Venture Kick has become an important actor in the Swiss startup scene. Using data from CrunchBase, we find that 22 percent of all the startups based in Switzerland founded between 2006 and 2019 that successfully completed a round of series A financing received money from Venture Kick. More importantly, seven of the thirteen best-ranked startups in this group, including MindMaze, Switzerland's first unicorn at $\$ 1+$ billion valuation, are Venture Kick alumnis. ${ }^{6}$ Venture Kick has therefore supported a disproportionate share of Switzerland's most successful startups. This record of identifying successful startups comforts the argument that Venture Kick is a credible and well-regarded source of certification.

The competition focuses on very early-stage ventures. To be eligible to participate, companies should not yet be incorporated, or only very recently, and cannot have already received funding from professional investors. These requirements imply that Venture Kick is usually involved in the startups' development before any other external investors or entrepreneurship program. Additionally, participating startups should have links with a Swiss academic institution or research center and plan to establish their company and create jobs in Switzerland. Conditions attached to the grant money have not changed

\footnotetext{
${ }^{5}$ According to the OECD, Switzerland had more than 70 million venture capital dollars invested per one million inhabitant in 2019.

${ }^{6}$ This ranking is based on CrunchBase's "CB Rank (Company)" consulted in April 2019.
} 
significantly during the years of our study, from 2007 to $2017 .{ }^{7}$ The first $\$ 10,000$ and $\$ 20,000$ are given as a grant with a moral obligation to repay in case the startup becomes successful. The final $\$ 100,000$ was initially also given as a grant but this changed in 2013 , when Venture Kick started taking a 1 to 3 percent share in the winning companies.

Venture Kick is structured as a three-stage, nine-month, private competition open several times a year to a new group of eight startups. Not all startups that apply are accepted; around 20 percent of applicants do not participate for a mixture of quality and logistical reasons. In the first stage (stage 1), startups pitch their business idea in front of a jury composed of an average of nine members. The judges are drawn from a pool of more than 150 private and institutional investors, startup experts and industry representatives. Each jury member grades the startups on eleven different criteria and votes for the startups they deem worthy of advancing to the next stage. ${ }^{8}$ These four winning startups receive $\$ 10 ’ 000$ and Venture Kick advertises the startups' victory on their website and Twitter. Winning startups also gain the right to display the competition's logo on their own website - a logo that will be identical whether the startup wins only stage 1 or all three stages. ${ }^{9}$ Finally, they secure access to the first two, out of three, kicker camps. These camps are two-day events where entrepreneurs receive mentoring and are put in contact with accomplished entrepreneurs and industry experts. Three months later in the second stage (stage 2), the startups have to present their business case in a similar setting to a different set of judges and two startups are selected for the third and final stage (stage 3). These two startups receive $\$ 20$ '000 as well as the same written publicity as in stage 1. They also gain access to the last kicker camp. Six months later in stage 3 , the last two startups compete to win the competition and the $\$ 100 ' 000$ prize attached to it. Once more, Venture Kick writes about the ultimate winner's success. Figure C.1 in appendix $\mathrm{C}$ illustrates the whole process. In addition, after each stage Venture Kick provides all participants, whether they won or lost, with a private feedback on their performance. This feedback includes a video of their presentation and subsequent Q\&A, their grades and a report that contains all the jury's comments and open questions about their project's viability.

\footnotetext{
${ }^{7}$ In 2019 , Venture Kick increased the money given in the second stage from $\$ 20,000$ to $\$ 40,000$, increasing the total amount received by the final winner from $\$ 130,000$ to $\$ 150,000$. The conditions attached to the funding have also changed with the initial $\$ 10,000$ still given as a grant but the remaining $\$ 140,000$ now a convertible loan with an interest rate of 5 percent. As these changes occurred outside of the time frame of our study, we do not look into their implications.

${ }^{8}$ Table A.1 in Appendix A shows the exact grading categories given during the three stages.

${ }^{9}$ Appendix B provides concrete examples of this publicity.
} 


\subsection{Data provided by Venture Kick}

Venture Kick has provided us with anonymized data on its competition and on 987 startups that have participated in a total of 305 rounds of competition over the years 2008 to 2017. ${ }^{10}$ These data form one of the strengths of our paper as all the startups have gone through exactly the same process, with the same set of rules and motivated by the same financial and non-financial incentives. Also, the relatively low number of participants per competition (a maximum of eight) means that the judges have around 30 minutes to analyze each startup and can remain consistent in their grading. As this process is repeated up to three times, each startup that competes in stage 3 will have spent 90 minutes with Venture Kick's judges. This setup contrasts with previous studies. Howell (2019)'s larger sample includes 87 different competitions that each had between six to 275 participants and one to 178 judges. In McKenzie (2017), there is only one paper-based competition during which the 6000 applications are assessed by an algorithm and an evaluator. ${ }^{11}$ We exploit the consistency and quality of our grading data in our identification strategy, as explained in Section 5.

Venture Kick has recorded every grade and vote given by the jury members in all three stages since 2008 and has shared them with us. In stage 1, each judge grades the startups on ten elements summarized by a 'People' and a 'Project' grade and an eleventh grade denominated 'Gut Feeling.' In stages 2 and 3, the 'Gut Feeling' grade remains but the other ten grades are replaced by ten new grades summarized by a 'People \& Project' grade and an 'Achievements \& Development' grade. Grades are given on an absolute scale from 0 (worst) to 6 (best). This allows us to identify weaker cohorts, providing us with some useful variation in the quality of both losers and winners. Because the variance in grades given to different startups decreases through the stages as the quality of the participants becomes consistently higher, we standardize each grade at the stage level. For our analysis, we decided to aggregate our eleven grade variables into one single measure by using a principal component analysis (PCA). We use this approach because we have noticed that the grade variable it produces for each stage is a better predictor of future startup success than any other aggregation method (e.g. average of the grades). Table D.1 in Appendix D shows the eigenvalues of the PCA on all the grades given in stage 1. Using the Kaiser Criterion, dropping all components with eigenvalues below 1,

\footnotetext{
${ }^{10} 123$ of these competitions are stage 1 rounds, 123 are stage 2 and 59 are stage 3 .

${ }^{11}$ The first selection of 6000 applications is made by an algorithm after a rapid assessment (ten minutes approximately). In the second stage the remaining 4510 business plan applications are marked by an evaluator drawn from a team of 20 individuals, with a typical plan taking 30-45 minutes to mark.
} 
we retain only the first principal component that accounts for 76 percent of the variance in our grades. We interpret this first component as being a measure of startup quality. Moreover, we can see in Table D.2 that the first component loads similarly onto all our grades, which is what we would expect as startup quality should be reflected in all the grades. Henceforth, the grade variable we use in our analysis is the measure produced by our PCA, unless specified otherwise. On the startups themselves, we have data on their characteristics (e.g. industry, date of creation, gender of main founder, etc.).

\subsection{Data collected for our study}

In order to be able to test the predictions of our model we require data pertaining to both the decisions of the entrepreneurs and the investors. To capture the entrepreneur's decision to pursue their activity, we use data on startups' survival rates in the years after the competition. To capture the investor's decision to invest in a given startup, we use data on whether and how much startups are able to secure external funding in the years after the competition. The data collection process was performed under our close supervision by Venture Kick to preserve the anonymity of the startups' information.

To construct our annual survival variable, we manually verified both whether and when each of the 759 startups that competed between 2008 and 2015 stopped its activity during the period up to the 1st of January 2018. ${ }^{12}$ We followed the same process to obtain data on startup exit (IPO \& Acquisitions). To do so, we relied on the following sources. Cantonal registries of commerce; the startup's website status and activity - if the website was down we used the Internet Archive's Wayback Machine ${ }^{13}$ to find out when it stopped being active - ; LinkedIn's staff profile and startup pages; Facebook and Twitter activity; CrunchBase's databases and other resources like newspaper articles and Venture Kick's own resources. To build our funding variables, we manually collected funding information on CrunchBase for the 970 startups that competed between 2008 and 2017 for the period up until the 1st of January 2020. ${ }^{14}$ These data provide the number of funding rounds, their dates and the amount of funding received for all participating startups. We also used patent data from the PATSTAT database to measure the startups' innovation output and

\footnotetext{
${ }^{12}$ The survival status of the startups that competed in 2016 and 2017 was deemed "too young to tell" because most of them had less than 2 years of existence at the time of the data gathering process (i.e. spring to summer 2018).

${ }^{13}$ The Internet Archive is a San Francisco based non-profit digital library and its WayBack Machine archives the entire web: WayBack Machine.

${ }^{14}$ These data were collected in early 2020 and therefore contain two more years than the survival variable.
} 
matched 693 patents to 104 startups in our sample.

Note that having access to annual outcome data is not common in the literature. These data will allow us to differentiate between the short-term and long-term effect of the certification and prize money.

\subsection{Descriptive Statistics}

Table 1 shows descriptive statistics concerning the startups in our sample, depending on how far they progressed into the competition. This table yields interesting facts about the startups that participate in and win Venture Kick. The first finding is that ICT startups do not perform very well in the competition. Indeed, while they represent 43 percent of our sample, only 17 percent of the winners of stage 3 come from these two sectors. At the other end of the spectrum Medtech, Biotech and Electronics \& Mechanics startups are over-represented among the winners of stage 3 (58 percent). Similarly, two universities dominate the competition. The two federal institutes of technology in Lausanne (EPFL) and Zurich (ETHZ) represent 44 percent of the participants but 72 percent of the winners. Women entrepreneurs are clearly under-represented, with 89 percent of the startups having declared a man as the main founder. However, they exhibit roughly the same success rate as men.

On the competition itself, the judges' grading is consistent across stages. Startups that will eventually lose in stage 2 receive lower grades on average in stage 1 (4.22) than those that will lose in stage 3 nine months later (4.34), which themselves receive lower grades than the ultimate winner (4.49). Also, as could be expected, startups that go further in the competition tend to have a higher probability of survival, 27 percent of the startups that lost in stage 1 are alive five years after the competition versus 93 percent for startups that won the final stage (last column). They also tend to secure more financing, have more employees, produce more turnover and obtain more patents in the years following the competition. About 3.2 percent of the startups in our sample have been acquired, which is similar to figures reported in Howell (2019). Our data tell us that winning the competition is associated with better performances after the competition. However we cannot yet infer causality. We now turn to our empirical strategy to explore the causal impact(s) of venture competitions. 
Table 1: Descriptive statistics: Characteristics and Outcome

\begin{tabular}{|c|c|c|c|c|c|}
\hline & Full sample & Lost in Stage 1 & Lost in Stage 2 & Lost in Stage 3 & Winners \\
\hline & Mean & Mean & Mean & Mean & Mean \\
\hline \multicolumn{6}{|l|}{ Categories: } \\
\hline Software & 0.24 & 0.31 & 0.26 & 0.16 & 0.08 \\
\hline Internet \& Mobile & 0.19 & 0.20 & 0.20 & 0.18 & 0.09 \\
\hline Medtech & 0.12 & 0.07 & 0.13 & 0.17 & 0.23 \\
\hline Electronics \& Mechanics & 0.10 & 0.05 & 0.11 & 0.14 & 0.19 \\
\hline Biotech & 0.09 & 0.04 & 0.11 & 0.15 & 0.16 \\
\hline Cleantech & 0.07 & 0.04 & 0.09 & 0.10 & 0.09 \\
\hline Materials \& Chemicals & 0.03 & 0.03 & 0.04 & 0.03 & 0.02 \\
\hline Micro-Nano Technology & 0.03 & 0.01 & 0.02 & 0.06 & 0.07 \\
\hline Others & 0.05 & 0.09 & 0.04 & 0.02 & 0.02 \\
\hline \multicolumn{6}{|l|}{ Universities: } \\
\hline EPFL & 0.21 & 0.13 & 0.22 & 0.31 & 0.33 \\
\hline ETH & 0.23 & 0.17 & 0.25 & 0.26 & 0.39 \\
\hline \multicolumn{6}{|l|}{ Miscellaneous: } \\
\hline Main founder is a man & 0.89 & 0.86 & 0.94 & 0.88 & 0.88 \\
\hline Average grade in Stage 1 & 3.85 & 3.32 & 4.22 & 4.34 & 4.49 \\
\hline Average grade in Stage 2 & 3.97 & . & 3.56 & 4.25 & 4.40 \\
\hline Average grade in Stage 3 & 4.27 & . & . & 3.89 & 4.62 \\
\hline \multicolumn{6}{|l|}{ Outcomes: } \\
\hline Alive after 2 years & 0.61 & 0.36 & 0.70 & 0.84 & 1.00 \\
\hline Alive after 5 years & 0.52 & 0.27 & 0.59 & 0.73 & 0.93 \\
\hline Received Funding after 2 years & 0.19 & 0.06 & 0.19 & 0.30 & 0.46 \\
\hline Received Funding after 5 years & 0.22 & 0.07 & 0.19 & 0.35 & 0.62 \\
\hline No. of Funding rounds after 2 years & 0.40 & 0.20 & 0.25 & 0.53 & 0.72 \\
\hline No. of Funding rounds after 5 years & 0.81 & 0.48 & 0.51 & 0.93 & 1.40 \\
\hline No. of patents after 2 years & 0.22 & 0.04 & 0.15 & 0.28 & 0.51 \\
\hline No. of patents after 5 years & 1.74 & 0.15 & 1.49 & 2.42 & 3.05 \\
\hline No. of Employees after 2 years & 7.06 & . & 5.24 & 7.52 & 9.64 \\
\hline No. of Employees after 5 years & 14.70 & . & 11.39 & 13.71 & 20.63 \\
\hline Turnover after 5 years, $\mathrm{kCHF}$ & 810.85 & . & 351.12 & 656.98 & 1623.60 \\
\hline Acquired & 0.03 & 0.01 & 0.04 & 0.09 & 0.05 \\
\hline Observations & 983 & 433 & 267 & 129 & 121 \\
\hline
\end{tabular}

Note: This table presents descriptive statistics for the full sample and conditional on their results in the competition. Number of Rounds, Patents, Employees, and Turnover are reported for the sub-sample of startups that are still alive. The total number of observations for the first eleven outcome variables are respectively 713, 428, 945, 606, 432, 224, 468, 234, 331, 176 and 171. 


\section{$5 \quad$ Empirical Strategy}

Our key empirical challenges are to estimate the causal effect of winning Venture Kick and identify the underlying mechanisms (certification vs. cash prize). We explain below how we leverage the relative effect of winning stages 1,2 or 3 as proxies for the relative effect of certification and cash prize.

Winning in the Venture Kick competition acts a certification of quality to both outside investors and entrepreneurs. For potential investors, Venture Kick's certification of quality reduces the information asymmetry that typically hinders investment in startups. The jury's assessment and feedback also acts as a type revelation mechanism for entrepreneurs, informing them about the probability of success of their ventures. This information could cause winning startups to redouble their efforts and losing startups to cut their losses (Yu, 2019).

We argue that we can use stage 1 as a proxy for the certification effect because it is during this first stage that Venture Kick's certification effect mainly occurs. Indeed, as Venture Kick is intended for very early-stage startups that have not yet been scrutinized by professional investors, stage 1 plays a crucial certifying role. Participating in stage 1 provides startups with a feedback that is very often the first expert assessment of their potential, encouraging winners to pursue their ventures while discouraging losers. In addition, winning stage 1 usually provides startups with the first credible and informative signal of their quality for outside investors. This signal takes the shape of an award and some online publicity. ${ }^{15}$ It also comes in the form of greatly increased online visibility97 percent of the startups that won stage 1 have a profile on CrunchBase compared to only 23 percent of the losers. Furthermore, we argue that stage 1's $\$ 10,000$ cash prize is not consequential. ${ }^{16}$ To put this number in perspective, the median monthly salary in Switzerland stands at $\$ 6,500$.

Winning stage 2 is mainly about reinforcing the certification and learning effect of Venture Kick. Indeed, upon winning stage 2 startups receive $\$ 20,000$ and, as after stage 1 , some publicity. The money remains limited and the publicity is nothing new but it reinforces the certification effect.

The other main benefit of winning Venture Kick is the cash prize offered to its winners, which can alleviate some of the startups' financial constraints. They can help startups

\footnotetext{
${ }^{15}$ To view some endorsement and details of Venture Kick's publicity see Appendix B.

${ }^{16}$ One participant provided this quote on the matter: "If you look back the $\$ 10,000$ of the first Venture Kick award seems not much."
} 
hire and invest in the crucial early stages of their existence. Stage 3 is primarily associated with the cash prize effect: winning stage 3 yields $\$ 100,000$-more than three times the combined prizes for winning stages 1 and 2 -raising the total funding received to $\$ 130,000$. While startups might also benefit from being declared the ultimate winner of the competition, we argue that stage 3's certification is of much less significance than stage 1's. For one it is unlikely that, after having received positive comments in stages 1 and 2, the feedback received during Venture Kick's final stage will have much bearing on entrepreneurs' decision to pursue their venture. On top of that, as the two finalists will both be of high quality, winning stage 3 is not as informative a signal to investors as winning stage 1 where there is much greater heterogeneity in participants' quality.

When it comes to estimating the effect of winning each stage, we are faced with the problem of endogeneity. Indeed, treatment assignment, winning a stage of Venture Kick, is not random but is assigned to startups of higher quality. In our case, winning Venture Kick captures both how the 'treatment effect' of Venture Kick and the quality of the startup affect future success. The challenge lies in disentangling these two effects, which we overcome using detailed data on grades. As we show below, these grades are an informative reflection of the startups' intrinsic quality, and we use them to proxy for the differences in startups' quality, thereby isolating the treatment effect of winning a stage of Venture Kick. However, we will also implement alternative identification strategies for the sake of robustness.

\subsection{Grades as a reflection of a startup's quality}

The grades given by Venture Kick's judges are particularly insightful because each startup in our sample has been judged by the same type of jury with the same motivations and guidelines. We argue that these grades are an informative proxy for startup quality because they are a strong predictor of a startup's success during and after the competition. To see that judges' grades predict success in the competition we can simply look back at Table 1, which shows that the judges can, on average, already predict in stage 1 who the eventual winners of the competition will be. The average grade they give during the first stage to the startups that will eventually lose in stage 2 (4.22) is lower than for losers of stage 3 (4.34) and final winners (4.49). This cannot be due to favoritism or judges sticking with their first choice because the jury changes at each stage.

This ability to predict success also applies to post-competition performances. Figure 1 shows that there is a clear positive relationship between judges' grades and a startup's 
probability of raising subsequent external funding in the two years after the competition. ${ }^{17}$

Figure 1: Judges are able to accurately discern startups' true quality

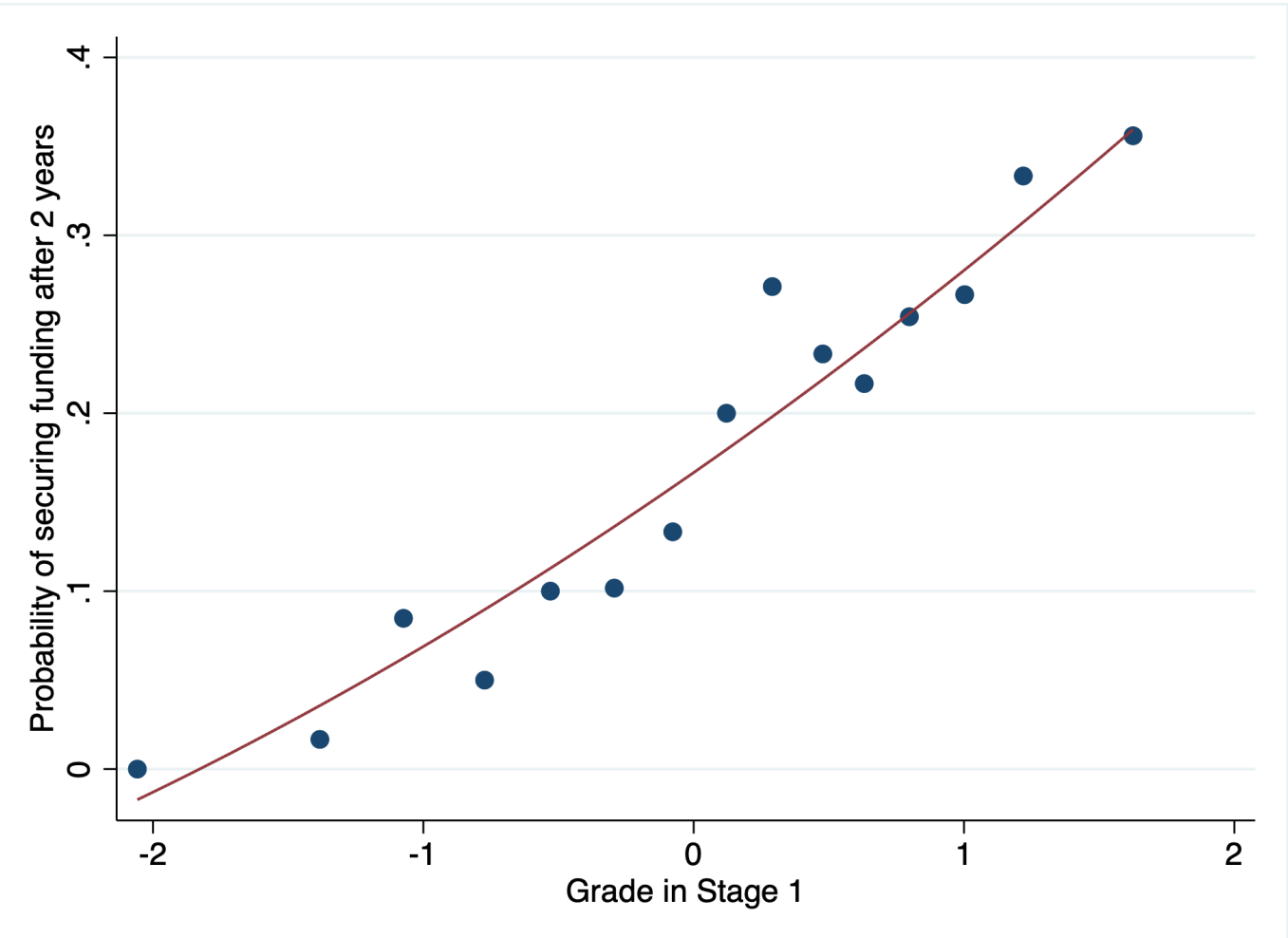

Note: This figure shows the strong positive relationship between judges' grades in stage 1 and the startup-specific probability of securing funding in the two years after the competition.

More formally, Table 2 displays the linear relationship between the grades given in stages 1, 2 and 3 and survival two to eight years after the competition. ${ }^{18}$ We see that these grades are a reliable predictor of future survival rate, especially in the short run. A one-standard-deviation increase in a judge's grade in stage 1 is associated with an increase in survival rate three years after the competition of 23 percentage points. In the longer run, as the sample size decreases and startups become very different from what they were during the competition, this relationship understandably fades. Stage 3's lower coefficients in the first three years of the competition are explained by the fact that there is very little variation in our dependent variable. Indeed, 100 percent of the winners of stage 3 are alive after two years, while 96 percent of them are still alive after three and

\footnotetext{
${ }^{17}$ Note that because grades are never made public, investors cannot condition on grades when deciding on funding.

${ }^{18} \mathrm{We}$ do not control for winning the stage at this point because we want to focus on the grades. Moreover, the relationship between grades and future performance remains the same whether we control for it or not.
} 
four years. Judges show the same capability to predict success if we use our funding variables as outcomes or if we control for winning stages of Venture Kick. In a nutshell, we argue that, because judges' grades are a informative predictor of future success, we can use them as a proxy to control for the unobservable quality of each startup.

Table 2: Relationship between judges' grades and future success

\begin{tabular}{|c|c|c|c|c|c|c|c|}
\hline & $\begin{array}{c}(1) \\
\text { Survival } 2\end{array}$ & $\begin{array}{c}(2) \\
\text { Survival } 3\end{array}$ & $\begin{array}{c}(3) \\
\text { Survival } 4\end{array}$ & $\begin{array}{c}(4) \\
\text { Survival } 5\end{array}$ & $\begin{array}{c}(5) \\
\text { Survival } 6\end{array}$ & $\begin{array}{c}(6) \\
\text { Survival } 7\end{array}$ & $\begin{array}{c}(7) \\
\text { Survival } 8\end{array}$ \\
\hline $\begin{array}{l}\text { Stage 1: } \\
\text { Standardized grade }\end{array}$ & $\begin{array}{l}0.198^{* * *} \\
(0.0271)\end{array}$ & $\begin{array}{l}0.222^{* * *} \\
(0.0285)\end{array}$ & $\begin{array}{l}0.202^{* * *} \\
(0.0307)\end{array}$ & $\begin{array}{l}0.185^{* * *} \\
(0.0325)\end{array}$ & $\begin{array}{l}0.144^{* * *} \\
(0.0421)\end{array}$ & $\begin{array}{l}0.117^{* *} \\
(0.0533)\end{array}$ & $\begin{array}{c}0.0439 \\
(0.0662)\end{array}$ \\
\hline $\begin{array}{l}\text { Stage 2: } \\
\text { Standardized grade }\end{array}$ & $\begin{array}{l}0.128^{* * *} \\
(0.0340)\end{array}$ & $\begin{array}{l}0.0943^{* *} \\
(0.0401)\end{array}$ & $\begin{array}{l}0.0757^{*} \\
(0.0431)\end{array}$ & $\begin{array}{c}0.0688 \\
(0.0514)\end{array}$ & $\begin{array}{c}0.0302 \\
(0.0485)\end{array}$ & $\begin{array}{c}0.0540 \\
(0.0596)\end{array}$ & $\begin{array}{c}0.0711 \\
(0.0775)\end{array}$ \\
\hline $\begin{array}{l}\text { Stage 3: } \\
\text { Standardized grade }\end{array}$ & $\begin{array}{l}0.0789^{* *} \\
(0.0339)\end{array}$ & $\begin{array}{l}0.0814^{* *} \\
(0.0349)\end{array}$ & $\begin{array}{l}0.127^{* * *} \\
(0.0419)\end{array}$ & $\begin{array}{c}0.152^{* *} \\
(0.0631)\end{array}$ & $\begin{array}{c}0.134^{*} \\
(0.0773)\end{array}$ & $\begin{array}{c}0.135 \\
(0.116)\end{array}$ & $\begin{array}{c}0.109 \\
(0.132)\end{array}$ \\
\hline Year FE & Yes & Yes & Yes & Yes & Yes & Yes & Yes \\
\hline Competition FE & Yes & Yes & Yes & Yes & Yes & Yes & Yes \\
\hline Industry FE & Yes & Yes & Yes & Yes & Yes & Yes & Yes \\
\hline University FE & Yes & Yes & Yes & Yes & Yes & Yes & Yes \\
\hline Observations stage 1 & 657 & 555 & 457 & 387 & 297 & 211 & 119 \\
\hline Observations stage 2 & 354 & 305 & 256 & 214 & 172 & 123 & 77 \\
\hline Observations stage 3 & 179 & 157 & 135 & 114 & 95 & 70 & 48 \\
\hline
\end{tabular}

Note: This table presents presents the linear regression of survival status on grades received during the stages 1 through 3 . The dependent variable is the survival status two years after the competition, Survival 2, in Column (1) all the way to eight years after the competition, Survival 8, in Column (7). The grade variable is standardized at the stage level. The level of observation is a startup in a competition round. Errors are clustered by competition round. ${ }^{*}, * *$, and ${ }^{* * *}$ denote statistical significance at $10 \%, 5 \%$, and $1 \%$ levels, respectively.

However, the ability of Venture Kick's judges to assess each startup's quality varies depending on the startup's technology, in line with previous findings in the literature. Our data shows that Venture Kick's experts are good at discerning between high- and lowquality early-stage startups in the hard science sectors (e.g. Medtech, Biotech, Materials \& Chemicals etc.) but less so in the ICT sectors. The top panel of Figure 2 shows the coefficients of the regressions in Table 2 using interactions terms to differentiate between two technology subgroups, one including ICT startups only and the other all remaining, mostly science-based, startups. ${ }^{19}$ The bottom panel does the same, changing the outcome

\footnotetext{
${ }^{19}$ The startups classified as science-based fall in the following categories: Medtech, Electronics \& Mechanics, Biotech, Cleantech, Materials \& Chemicals, Micro-Nano Technology and Others. ICT startups are those in the Internet \& Mobile and Software categories.
} 
variable to be whether or not a startup managed to secure funding after the competition. It reveals that the experts on Venture Kick's jury are not only very good at evaluating the quality of science startups but also that their grading remains informative in the long run. The grading received by an ICT startup is still instructive but less so; it provides little information about the startup's probability of survival six or more years after the competition (an admittedly distant horizon for startups). This heterogeneity in the judges' grades predictive power is important. Indeed, an institution's certification of quality relies on its ability to correctly assess said quality. Because it is harder for experts to objectively evaluate ICT startups, Venture Kick's certification of their quality should be less trusted than for science startups. Therefore as we hypothesized in Section 3.1, winning stage 1 should be more valuable for science ventures than for software-focused ones. This is exactly what we observe, as we will discuss in Section 7. This varying ability that judges display in evaluating startups from different technology types that both Scott et al. (2020) and our paper highlight merits further study. It would be interesting, for example, to discover whether science-based startups are indeed intrinsically easier to assess, as we argue, or if this phenomenon reflects something else (e.g. scientists might be over-represented in juries and better at evaluating science-based startups).

\section{Testing Prediction 1: Average Causal Impact}

In this section we test empirically Proposition 1 that, venture competitions are useful, mainly because they provide an informative certification of quality. To do so we estimate the causal effect of each stage by implementing our main identification strategy captured by Equation 1. Then, to ensure the robustness of our results we use three alternative identification strategies: introducing new control variables, a sharp regression discontinuity design and a propensity score matching. We describe these approaches in Section 6.2. Finally, we test in Section 6.3 the two predictions that result from Proposition 1; Lemma 1.a: entrepreneurs react more strongly to a negative certification than a positive one and Lemma 1.b: marginal startups are most affected by certification.

Having established that grades are an informative predictor of a startup's future success, we can utilize them to estimate the causal effect of winning the three stages of the competition as follows:

$$
Y_{i}=\alpha_{i, s}+\delta_{1} \text { WinsStage }_{i, s}+\beta_{1} \text { StartupQuality }_{i, s}+\gamma_{\text {year } / \text { comp } / \text { ind } / \text { uni }}+\epsilon_{i, s}
$$


Figure 2: Relationship between a one-std.-deviation increase in grades and future outcomes
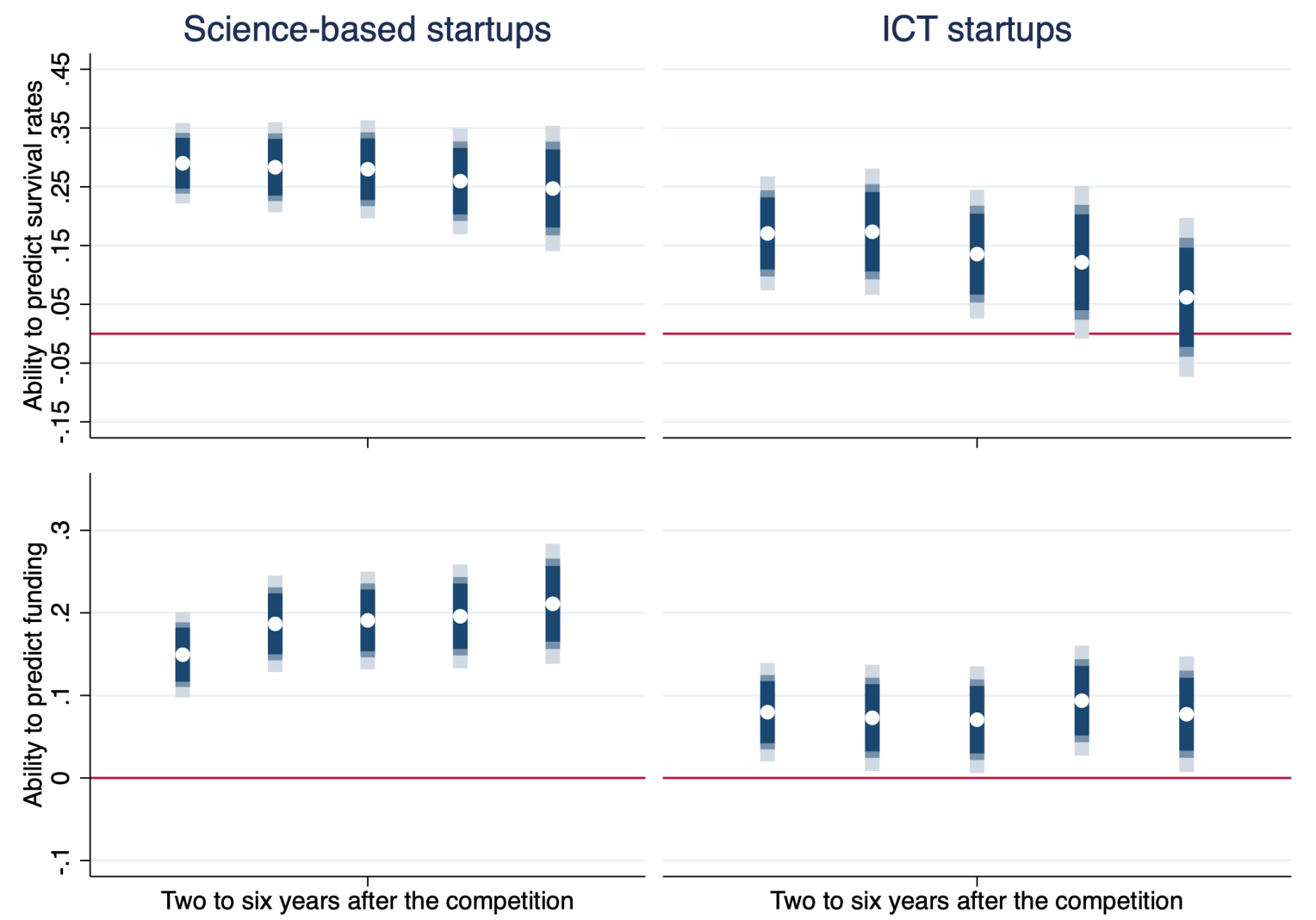

Note: This figure's top panel displays the coefficients of Table 2 (i.e. how well the judges' grades predict survival two years after the competition) using interactions terms to differentiate between technology subgroups. The bottom panel shows the relationship between grades and financing after the competition. Errors are clustered by competition round. The confidence intervals are at the $10 \%, 5 \%$ and $1 \%$ levels, respectively.

where $i$ represents the startup and $s$ the stage. The dependent variable $Y_{i s}$ is the survival rate or a funding outcome. The Survival $X$ variable takes a value of 1 if a startup is alive a given number of years after the competition and a 0 otherwise. Funding $X$ is also a binary variable that takes the value of 1 if a startup secures non-Venture Kick funding after the competition. Finally, Rounds $X$ is the number of funding rounds that a startup manages to secure after the competition and takes values from 0 to 10 . Fixed effects for Year $\left(\gamma_{\text {year }}\right)$, Competition $\left(\gamma_{\text {comp }}\right)$, Industry $\left(\gamma_{\text {ind }}\right)$ and University $\left(\gamma_{\text {uni }}\right)$ are also added. $\delta_{1}$ captures the effect of winning each stage while StartupQuality ${ }_{i, s}$ is captured by the startup's grading. Given the data structure and the fact that one firm's win is another firm's loss, errors are clustered by competition round. We use OLS as our 
main specification. ${ }^{20}$ Additionally, we implement errors-in-variables regressions that can account for the fact that grades might be an imperfect proxy of startup quality.

\subsection{The average effect of Venture Kick}

Table 3 displays estimates of Equation (1). Column (1) shows that without any controls, winning stage 1 is associated with an increase in survival two years after the competition of 45 percentage points. This effect captures both the treatment effect and the effect of startup quality. Column (2) introduces Year, Competition, Industry and University fixed effects. Column (3) adds the grade variable to capture the quality of the startups and is our main specification. We find that winning stage 1 increases survival after two years by 22 percentage points. However, winning stages 2 and 3 does not seem to have any significant impact on startups' survival once we control for their quality. This result holds when we consider longer time periods (columns (4) and (5)).

Columns (6) and (7) respectively present the effect of winning on the probability of receiving further funding and on the number of funding rounds concluded in the two years following the competition. Here, we focus only on the first two years to prevent our funding outcome from being too influenced by the startups' survival rates. Indeed, startups that live longer will mechanically have a higher probability of receiving funding over their lifetime. ${ }^{21}$ As with survival rates, winning stage 1 has a significant positive impact. It increases the probability of securing financing in the two years after the competition by 14.3 percentage points, and increases the number of funding rounds by 0.25 . Once again, winning stage 2 or stage 3 - with its substantial cash prize - does not seem to have any significant impact on startups' future success.

To summarize, we find that the first stage of Venture Kick is the only one that has a significant causal impact on startups' future performances, consistent with a certification effect. Moreover, our results show that certification informs both entrepreneurs' decision to pursue their venture (survival rates) and investors (funding outcomes). Our results support our first prediction that what matters most for the startups that participate in venture competitions is the certification of quality that winning a stage provides them

\footnotetext{
${ }^{20}$ We have also estimated logit models and obtained similar findings. We report OLS regression results because they are easier to interpret. Furthermore, OLS does as well as logit, if not better, in estimating causal effects of treatment (Angrist, 2001).

${ }^{21}$ Focusing only on the first two years puts short- and long-lived startups on an equal footing when it comes to the amount of time available to them to search for financing, as even the weakest startups will be alive for a good part of these two years. It is also not too restrictive as three quarters of startups that manage to secure at least one external funding do so in the first two years after the competition.
} 
with. We explore these findings in more detail in Section 6.3. Comparatively, the cash prize does not seem crucial to a startup's success, in line with our predictions.

Table 3: Main specification: Effect of winning stages 1, 2 and 3

\begin{tabular}{|c|c|c|c|c|c|c|c|}
\hline & \multicolumn{5}{|c|}{ Survival rates $\mathrm{X}$ years after the competition } & \multicolumn{2}{|c|}{ Funding after comp. } \\
\hline & $\begin{array}{c}1) \\
\text { Survival } 2\end{array}$ & $\begin{array}{c}(2) \\
\text { Survival } 2\end{array}$ & $\begin{array}{c}(3) \\
\text { Survival } 2\end{array}$ & $\begin{array}{c}(4) \\
\text { Survival } 4\end{array}$ & $\begin{array}{c}(5) \\
\text { Survival } 6\end{array}$ & $\begin{array}{c}(6) \\
\text { Funding } 2\end{array}$ & $\begin{array}{c}(7) \\
\text { Rounds } 2\end{array}$ \\
\hline $\begin{array}{l}\text { First regression: Stage } 1 \\
\text { Wins Stage } 1\end{array}$ & $\begin{array}{l}0.437^{* * *} \\
(0.0351)\end{array}$ & $\begin{array}{l}0.373^{* * *} \\
(0.0491)\end{array}$ & $\begin{array}{l}0.220^{* * *} \\
(0.0683)\end{array}$ & $\begin{array}{l}0.223^{* * *} \\
(0.0798)\end{array}$ & $\begin{array}{l}0.206^{*} \\
(0.105)\end{array}$ & $\begin{array}{l}0.143^{* * *} \\
(0.0427)\end{array}$ & $\begin{array}{l}0.249^{* * *} \\
(0.0890)\end{array}$ \\
\hline Standardized grade & & & $\begin{array}{l}0.119^{* * *} \\
(0.0353)\end{array}$ & $\begin{array}{c}0.120^{* *} \\
(0.0452)\end{array}$ & $\begin{array}{c}0.0739 \\
(0.0615)\end{array}$ & $\begin{array}{l}0.0550^{* *} \\
(0.0229)\end{array}$ & $\begin{array}{l}0.134^{* * *} \\
(0.0463)\end{array}$ \\
\hline $\begin{array}{l}\text { Second regression: Stage } 2 \\
\text { Wins Stage } 2\end{array}$ & $\begin{array}{l}0.157^{* * *} \\
(0.0397)\end{array}$ & $\begin{array}{c}0.132^{* *} \\
(0.0558)\end{array}$ & $\begin{array}{l}-0.0541 \\
(0.0666)\end{array}$ & $\begin{array}{c}0.0772 \\
(0.0998)\end{array}$ & $\begin{array}{c}0.151 \\
(0.124)\end{array}$ & $\begin{array}{c}0.0270 \\
(0.0836)\end{array}$ & $\begin{array}{c}0.141 \\
(0.184)\end{array}$ \\
\hline Standardized grade & & & $\begin{array}{l}0.148^{* * *} \\
(0.0429)\end{array}$ & $\begin{array}{c}0.0439 \\
(0.0536)\end{array}$ & $\begin{array}{l}-0.0344 \\
(0.0622)\end{array}$ & $\begin{array}{l}0.129^{* * *} \\
(0.0408)\end{array}$ & $\begin{array}{c}0.239^{* *} \\
(0.0985)\end{array}$ \\
\hline $\begin{array}{l}\text { Third regression: Stage } 3 \\
\text { Wins Stage } 3\end{array}$ & $\begin{array}{l}0.105^{* * *} \\
(0.0311)\end{array}$ & $\begin{array}{c}0.117^{* *} \\
(0.0476)\end{array}$ & $\begin{array}{c}0.0477 \\
(0.0479)\end{array}$ & $\begin{array}{l}-0.0535 \\
(0.0946)\end{array}$ & $\begin{array}{c}-0.0386 \\
(0.177)\end{array}$ & $\begin{array}{c}0.141 \\
(0.127)\end{array}$ & $\begin{array}{c}0.262 \\
(0.311)\end{array}$ \\
\hline Standardized grade & & & $\begin{array}{c}0.0578 \\
(0.0413)\end{array}$ & $\begin{array}{c}0.151^{* *} \\
(0.0688)\end{array}$ & $\begin{array}{c}0.150 \\
(0.103)\end{array}$ & $\begin{array}{c}0.0466 \\
(0.0688)\end{array}$ & $\begin{array}{c}0.137 \\
(0.166)\end{array}$ \\
\hline Year FE & No & Yes & Yes & Yes & Yes & Yes & Yes \\
\hline Competition FE & No & Yes & Yes & Yes & Yes & Yes & Yes \\
\hline University FE & No & Yes & Yes & Yes & Yes & Yes & Yes \\
\hline Industry FE & No & Yes & Yes & Yes & Yes & Yes & Yes \\
\hline Observations stage 1 & 713 & 671 & 671 & 466 & 303 & 893 & 893 \\
\hline Observations stage 2 & 402 & 354 & 353 & 255 & 171 & 446 & 446 \\
\hline Observations stage 3 & 200 & 178 & 178 & 135 & 95 & 216 & 216 \\
\hline
\end{tabular}

Note: This table presents estimates of the effect of winning stages 1,2 and 3 and grading on whether the startups survived or secured financing a given number of years after the competition. It uses variants of Equation (1) with varying levels of fixed effects. Columns (1) through (5) use the survival status after the competition as the dependent variable. Column (6)'s dependent variable is whether the startup secured financing two years after the competition while Column (7)'s is the number of funding rounds secured within the same time frame. The level of observation is a startup in a competition round. Errors are clustered by competition round. ${ }^{*}, * *$, and ${ }^{* * *}$ denote statistical significance at $10 \%, 5 \%$, and $1 \%$ levels, respectively.

Finally, because our main identification strategy relies on judges' grading, we want to test the sensitivity of our results to changes in grades' reliability. Indeed, despite the fact that the grades capture the best guess of, on average, nine experts about the startup quality, these grades remain an imperfect proxy of quality. In an extension to the analysis, we estimate errors-in-variables regression models in which we allow quality to be observed imperfectly. Specifically, we consider that grades are measured with some additive noise that downweighs their effect. We find that using this approach keeps our results unchanged. Table E.1 in Appendix E shows that assuming that the grade 
variable has a reliability of 0.7 - the noise represents 30 percent of the total variancestage 1 continues to be the only stage with a significantly positive effect. While this approach has its limits, ${ }^{22}$ it shows that allowing for some level of imprecision in judges' grading does not significantly alter the direction and size of our results.

\subsection{Alternative identification strategies}

\subsubsection{Introducing additional control variables}

To test the robustness of our findings we introduce a variety of control variables. First, we control for motivation, which, like quality, could impact a startup's performances both during and after Venture Kick. We proxy motivation by looking at the voluntary participation of startups in Venture Kick's kicker camps. Our motivation metric is a dummy variable that takes a value of 1 if a startup that loses in stage 2 still goes to the second kicker camp, if a startup that loses in stage 3 still goes to the final kicker camp and finally if a winner of the competition went to the three kicker camps to which it has access. This proxy is not perfect however, as a startup that lost in stage 1 has no opportunity to show its motivation by participating in a kicker camp.

Second, Clingingsmith and Shane (2017) have shown that founders who pitch their startups first or second in a competition are evaluated more harshly than the others. We therefore control for the order in which the participants pitched to the jury. Third, we use other grade variables to verify that our results do not depend on the use of a PCA to aggregate them. We test with both an average of the eleven grades and the three sub-categories in which the grades are categorized.

We will also use two new funding outcome variables, namely Funding and Rounds, which capture total funding and number of rounds concluded over the whole sample, irrespective of the elapsed time. This approach might introduce a survival bias as discussed in Section 6.1. However, it also allows us to consider the funding activity that occurs more than two years after the competition.

Table 4 displays the results. Comparing our main specification (column (3) in Table 3) with column (1) in Table 4, we see that while our Motivation variable correlates with future success, the effect of winning stage 1 persists. Column (2) shows that controlling for the order of passage does not change our findings. Columns (3), (4) and (5) confirm that our results do not depend on which grade we use. We see however that the PCA

\footnotetext{
${ }^{22}$ We are forced, for example, to drop all of our fixed effects due to the limited number of observations in our sample.
} 
grade in Table 3 has a slightly stronger relationship with survival than the average grade in column (3). Columns (4) and (5) tell us that in stage 1, the project grade is a slightly better predictor of future success than the team grade and a much better one than the gut feeling grade. This finding contributes to the horse vs. jockey debate (Kaplan et al., 2009), a discussion on whether it is the quality of the team or of the project that matters more to a startup's success. Finally, the effect of stage 1 on funding remains the same when using these alternative funding variables.

We apply the same robustness checks to the effects of stages 2 and 3 (see Tables E.2 and E.3). Most of the results remain unchanged with one notable exception. Columns (6) and (7) in Table E.2 suggest that winning stage 2 could also have a positive impact on funding opportunities after the competition. However, it is difficult to estimate how much of this effect on long-term funding opportunities is influenced by the fact that winning startups survive longer than losing startups.

\subsubsection{Regression Discontinuity Design}

Next, we assess the robustness of our results by implementing a regression discontinuity design (RDD). We exploit the sharp discontinuity between the startups ranked fourth and fifth in the first stage, the former going on to the second stage and the latter being eliminated from the competition. We use the startup's rank as the running variable. While having only eight startups per competition raises the issues of the discreteness of our running variable, a setting with eight competitors can still provide useful information, as shown by Howell (2017)'s study on grant competitions with an average of ten applicants. ${ }^{23}$ Figure 3 confirms that the use of an RDD is warranted, at least in stage 1. We can see on the top-left panel that there is a clear discontinuity in survival rates and funding probabilities between the startups ranked fourth and fifth in stage 1 . The other four panels show that there is no discontinuity around the cutoff in the probability of being an ICT startup, being the fifth startup to pitch, having a man as the main founder, or being linked to EPFL. ${ }^{24}$ There is also no discontinuity at the cutoff for the other precompetition characteristics. Our design, therefore, satisfies the RDD requirement that there should not be any discontinuity in our other baseline covariates that could cause a discontinuity in our outcome variable of interest. Finally for an RDD to be valid, we need to ensure that treatment does not cause rank. This requirement is easily met because

\footnotetext{
${ }^{23}$ Note that we cannot implement the RDD in stage 3 due to the reduced number of participants on each side of the cutoff. This is the reason why the RDD is not our preferred identification strategy.

${ }^{24} \mathrm{EPFL}$ is one of the two largest research-intensive technical universities in Switzerland.
} 
Table 4: Control variables: Effect of winning stage 1

\begin{tabular}{|c|c|c|c|c|c|c|c|}
\hline & \multirow{2}{*}{$\begin{array}{c}\frac{\text { Motivation }}{(1)} \\
\text { Survival } 2\end{array}$} & \multirow{2}{*}{ 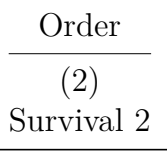 } & \multicolumn{3}{|c|}{ Other grade variables } & \multicolumn{2}{|c|}{ Funding } \\
\hline & & & $\begin{array}{c}(3) \\
\text { Survival } 2\end{array}$ & $\begin{array}{c}(4) \\
\text { Survival } 2\end{array}$ & $\begin{array}{c}(5) \\
\text { Funding } 2 \\
\end{array}$ & $\begin{array}{c}(6) \\
\text { Funding }\end{array}$ & $\begin{array}{c}(7) \\
\text { Rounds }\end{array}$ \\
\hline Wins Stage 1 & $\begin{array}{c}0.162^{* *} \\
(0.0709)\end{array}$ & $\begin{array}{l}0.215^{* * *} \\
(0.0692)\end{array}$ & $\begin{array}{l}0.221^{* * *} \\
(0.0693)\end{array}$ & $\begin{array}{l}0.238^{* * *} \\
(0.0700)\end{array}$ & $\begin{array}{l}0.160^{* * *} \\
(0.0439)\end{array}$ & $\begin{array}{l}0.140^{* * *} \\
(0.0454)\end{array}$ & $\begin{array}{l}0.253^{*} \\
(0.142)\end{array}$ \\
\hline Standardized grade & $\begin{array}{l}0.115^{* * *} \\
(0.0357)\end{array}$ & $\begin{array}{l}0.125^{* * *} \\
(0.0369)\end{array}$ & & & & $\begin{array}{c}0.0919^{* * *} \\
(0.0252)\end{array}$ & $\begin{array}{l}0.331^{* * *} \\
(0.0754)\end{array}$ \\
\hline Motivation & $\begin{array}{l}0.187^{* * *} \\
(0.0487)\end{array}$ & & & & & & \\
\hline $\begin{array}{l}\text { Standardized average } \\
\text { grade }\end{array}$ & & & $\begin{array}{l}0.114^{* * *} \\
(0.0350)\end{array}$ & & & & \\
\hline $\begin{array}{l}\text { Standardized Gut } \\
\text { Feeling grade }\end{array}$ & & & & $\begin{array}{l}-0.0488 \\
(0.0807)\end{array}$ & $\begin{array}{l}-0.0629 \\
(0.0575)\end{array}$ & & \\
\hline $\begin{array}{l}\text { Standardized Team } \\
\text { grade }\end{array}$ & & & & $\begin{array}{c}0.0713 \\
(0.0531)\end{array}$ & $\begin{array}{c}0.0568 \\
(0.0386)\end{array}$ & & \\
\hline $\begin{array}{l}\text { Standardized Project } \\
\text { grade }\end{array}$ & & & & $\begin{array}{c}0.0985 \\
(0.0642)\end{array}$ & $\begin{array}{c}0.0598 \\
(0.0478)\end{array}$ & & \\
\hline Order FE & No & Yes & No & No & No & No & No \\
\hline Year FE & Yes & Yes & Yes & Yes & Yes & Yes & Yes \\
\hline Competition FE & Yes & Yes & Yes & Yes & Yes & Yes & Yes \\
\hline University FE & Yes & Yes & Yes & Yes & Yes & Yes & Yes \\
\hline Industry FE & Yes & Yes & Yes & Yes & Yes & Yes & Yes \\
\hline Observations & 671 & 671 & 671 & 669 & 891 & 909 & 909 \\
\hline$R^{2}$ & 0.427 & 0.424 & 0.412 & 0.417 & 0.309 & 0.327 & 0.316 \\
\hline
\end{tabular}

Note: This table presents estimates of Equation (1) with additional controls, for stage 1. Column (1) controls for motivation, Column (2) for the order of passage during the competition, Columns (3) to (5) uses alternative grade variables. For the dependent variable, Columns (1) to (4) use the survival status two years after the competition as the dependent variable. Column (5) uses whether a startup received funding in the two years after the competition. Columns (6) and (7) introduce two new dependent variables, namely whether the startup secured financing after the competition, Funding, and the number of funding rounds secured, Rounds. The level of observation is a startup in a competition round. Errors are clustered by competition round. *, ${ }^{* *}$, and ${ }^{* * *}$ denote statistical significance at $10 \%, 5 \%$, and $1 \%$ levels, respectively.

the winners are determined after the ranks are established. Note that because the ranks around the cutoff are, by construction, equally populated there is no need to show a density test à la McCrary (2008).

Table 5 displays the results of our RDD for stages 1 and 2. Columns (1), (2), (4) and (5) are parametric RDDs using the startup's rank in the competition as the running variable, allowing for a different slope coefficient on each side of the cutoff. Columns (3) and (6) are non-parametric RDDs with a bandwidth of one rank, meaning that in stage 1 we only focus on the startups ranked fourth (best loser) and fifth (worst winner). We can see that our main results hold: stage 1 is the only stage that has a positive and significant 
Figure 3: RDD: Discontinuities around the cutoff in stage 1
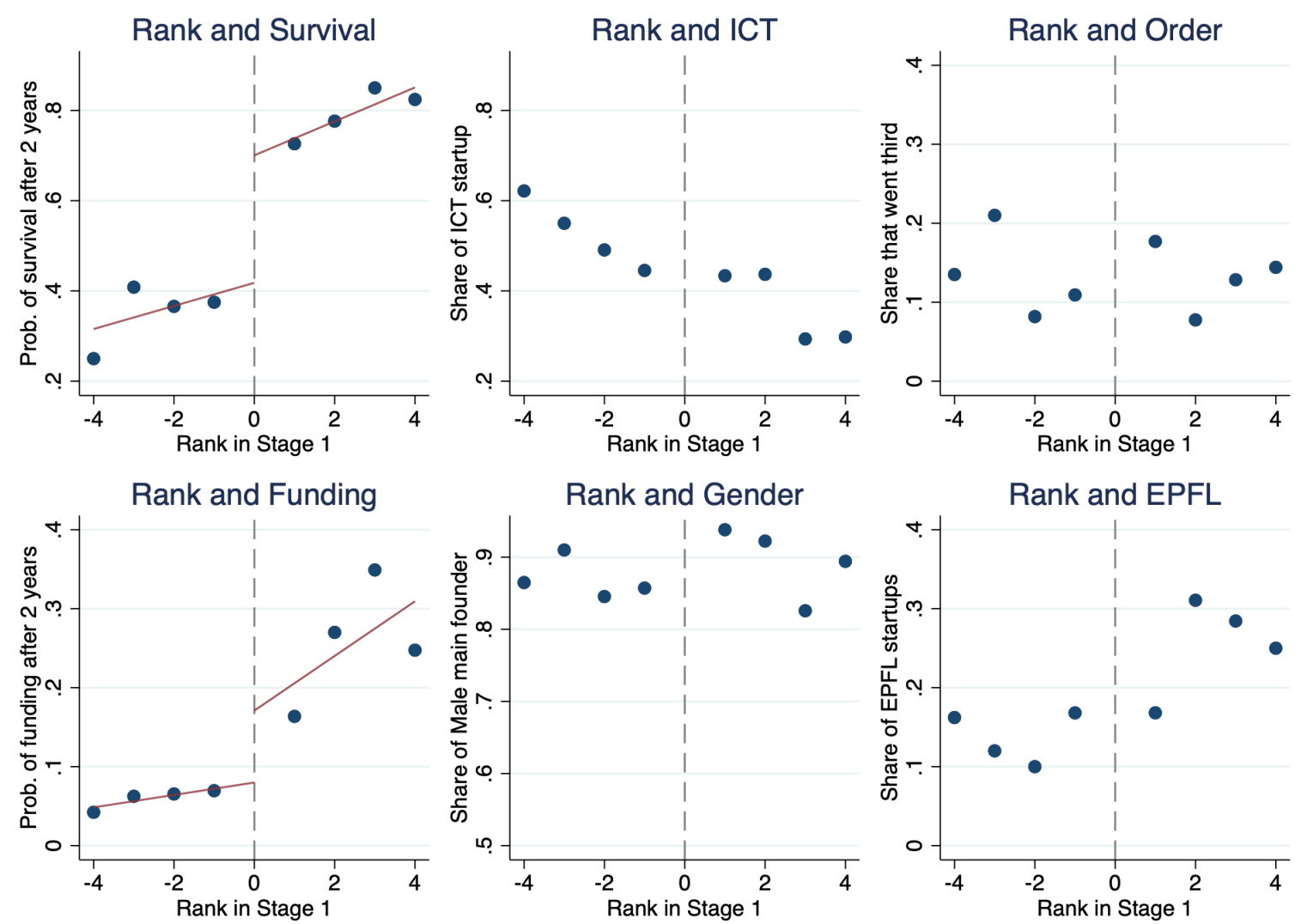

Note: This figure presents the (dis-)continuity of both our two main outcome variables as well as four selected baseline covariates around the cutoff. This values on display are the probabilities of observing startup-specific outcomes and characteristics at the time of the competition by rank in the first stage. The sample consists of all ventures in the first stage and the result holds for all covariates.

causal impact on future performances. The magnitude of the effect of winning stage 1 remains similar. Winning stage 1 now increases survival two years after the competition by 23 (or 35) percentage points and increases the probability of getting funded by 10 percentage points and the number of rounds secured by 0.27 . We see that the effect of winning stage 2 on funding that was hinted at in Table E. 2 has disappeared.

\subsubsection{Propensity score matching}

Our third approach to establish the robustness of the findings involves using a propensity score matching (PSM) estimation. This technique allows us to compare similar startups whose only significant observed difference lies in whether or not they have won a given 
Table 5: RDD: Effect of winning stages 1 and 2

\begin{tabular}{|c|c|c|c|c|c|c|}
\hline & \multicolumn{3}{|c|}{ RDD: Survival } & \multicolumn{3}{|c|}{ RDD: Funding } \\
\hline & $\begin{array}{c}(1) \\
\text { Survival } 2\end{array}$ & $\begin{array}{c}(2) \\
\text { Survival } 2\end{array}$ & $\begin{array}{c}(3) \\
\text { Survival } 2\end{array}$ & $\begin{array}{c}(4) \\
\text { Rounds } 2\end{array}$ & $\begin{array}{c}(5) \\
\text { Funding } 2\end{array}$ & $\begin{array}{c}(6) \\
\text { Funding } 2\end{array}$ \\
\hline $\begin{array}{l}\text { First regression: Stage } 1 \\
\text { Wins Stage } 1\end{array}$ & $\begin{array}{l}0.283^{* * *} \\
(0.0895)\end{array}$ & $\begin{array}{l}0.232^{* *} \\
(0.109)\end{array}$ & $\begin{array}{l}0.351^{* * *} \\
(0.0712)\end{array}$ & $\begin{array}{l}0.267^{* *} \\
(0.125)\end{array}$ & $\begin{array}{c}0.105 \\
(0.0667)\end{array}$ & $\begin{array}{l}0.0956^{* *} \\
(0.0435)\end{array}$ \\
\hline Losers' Rank & $\begin{array}{c}0.0256 \\
(0.0270)\end{array}$ & $\begin{array}{c}0.0120 \\
(0.0306)\end{array}$ & & $\begin{array}{l}0.00285 \\
(0.0248)\end{array}$ & $\begin{array}{l}0.00378 \\
(0.0143)\end{array}$ & \\
\hline Winners' Rank & $\begin{array}{l}0.0376^{*} \\
(0.0217)\end{array}$ & $\begin{array}{l}0.0478^{*} \\
(0.0268)\end{array}$ & & $\begin{array}{c}0.0484 \\
(0.0336)\end{array}$ & $\begin{array}{l}0.0348^{* *} \\
(0.0174)\end{array}$ & \\
\hline $\begin{array}{l}\text { Second regression: Stage } 2 \\
\text { Wins Stage } 2\end{array}$ & $\begin{array}{r}-0.0469 \\
(0.114)\end{array}$ & $\begin{array}{l}-0.130 \\
(0.146)\end{array}$ & $\begin{array}{c}0.0830^{*} \\
(0.0482)\end{array}$ & $\begin{array}{l}-0.228 \\
(0.350)\end{array}$ & $\begin{array}{l}-0.169 \\
(0.162)\end{array}$ & $\begin{array}{c}0.0522 \\
(0.0582)\end{array}$ \\
\hline Losers' Rank & $\begin{array}{c}0.114^{*} \\
(0.0680)\end{array}$ & $\begin{array}{c}0.122 \\
(0.0992)\end{array}$ & & $\begin{array}{l}0.320^{* *} \\
(0.143)\end{array}$ & $\begin{array}{l}0.181^{* * *} \\
(0.0650)\end{array}$ & \\
\hline Winners' Rank & $\begin{array}{c}0.0159 \\
(0.0442)\end{array}$ & $\begin{array}{c}0.0499 \\
(0.0589)\end{array}$ & & $\begin{array}{c}0.102 \\
(0.182)\end{array}$ & $\begin{array}{c}0.0619 \\
(0.0798)\end{array}$ & \\
\hline Year FE & No & Yes & No & Yes & Yes & No \\
\hline Competition FE & No & Yes & No & Yes & Yes & No \\
\hline University FE & No & Yes & No & Yes & Yes & No \\
\hline Industry FE & No & Yes & No & Yes & Yes & No \\
\hline Observations stage 1 & 603 & 603 & 172 & 804 & 804 & 224 \\
\hline Observations stage 2 & 326 & 326 & 180 & 413 & 413 & 228 \\
\hline
\end{tabular}

Note: This table presents results of linear regressions using regression discontinuity designs (RDDs). The running variable is a startup's rank within its competition round. A higher rank is better; in stage 1, -4 is the worst and 4 the best. Columns (1) and (2) display parametric RDDs using the entire sample. Columns (3) is a non-param. RDDs comparing startups one rank around the cutoff. Columns (4), (5) and (6) use both approaches on funding variables. The level of observation is a startup in a competition round. Errors are clustered by competition round. ${ }^{*},{ }^{*}$, and ${ }^{* * *}$ denote statistical significance at $10 \%, 5 \%$, and $1 \%$ levels, respectively.

stage of Venture Kick. We match startups one to one to their nearest neighbor based on the propensity scores. This score is computed using the startups' quality, proxied by the grade variable, as well as their technology, whether they have links with EPFL or ETHZ, whether their main founder is a man and the year of the competition. If our matching process is adequate, the matched treatment and control groups should have balanced covariates and propensity score. Figures F.1 and F.2 in Appendix F show respectively for stages 1 and 3 how the balance of scores between winning and losing startups is greatly improved in our matched sample. One common issue is that the very best winning 
startups, based on the grade or propensity score, are understandably harder to match to equivalent losing startups. Therefore our PSM will most likely overestimate the effect of winning Venture Kick's stages. Table 6 shows the results of our PSM. Once more only a win in stage 1 has a consistent significant positive impact on future performances. Moreover, the estimated treatment effect is very close in size to those estimated using the other identification strategies.

Table 6: PSM: Treatment effect of winning stage 1, 2 and 3

\begin{tabular}{|c|c|c|c|c|}
\hline & \multicolumn{2}{|c|}{ ATE } & \multicolumn{2}{|c|}{ ATET } \\
\hline & $\begin{array}{c}(1) \\
\text { Survival } 2\end{array}$ & $\begin{array}{c}(2) \\
\text { Rounds } 2\end{array}$ & $\begin{array}{c}(3) \\
\text { Survival } 2\end{array}$ & $\begin{array}{l}(4) \\
\text { Rounds } 2\end{array}$ \\
\hline $\begin{array}{l}\text { First regression: Stage } 1 \\
\text { Wins Stage } 1\end{array}$ & $\begin{array}{l}0.320^{* * *} \\
(0.0471)\end{array}$ & $\begin{array}{l}0.305^{* *} \\
(0.123)\end{array}$ & $\begin{array}{l}0.180^{* * *} \\
(0.0694)\end{array}$ & $\begin{array}{c}0.326^{* * *} \\
(0.112)\end{array}$ \\
\hline $\begin{array}{l}\text { Second regression: Stage } 2 \\
\text { Wins Stage } 2\end{array}$ & $\begin{array}{c}0.0708 \\
(0.0667)\end{array}$ & $\begin{array}{l}0.204^{*} \\
(0.104)\end{array}$ & $\begin{array}{l}0.0426 \\
(0.102)\end{array}$ & $\begin{array}{l}0.342^{* *} \\
(0.149)\end{array}$ \\
\hline $\begin{array}{l}\text { Third regression: Stage } 3 \\
\text { Wins Stage } 3\end{array}$ & $\begin{array}{l}0.0618^{* * *} \\
(0.0222)\end{array}$ & $\begin{array}{l}0.250^{* * *} \\
(0.0859)\end{array}$ & $\begin{array}{c}0.0217 \\
(0.0199)\end{array}$ & $\begin{array}{c}0.193 \\
(0.140)\end{array}$ \\
\hline $\begin{array}{l}\text { Observations stage } 1 \\
\text { Observations stage } 2 \\
\text { Observations stage } 3\end{array}$ & $\begin{array}{l}671 \\
353 \\
178\end{array}$ & $\begin{array}{l}893 \\
446 \\
216\end{array}$ & $\begin{array}{l}671 \\
353 \\
178\end{array}$ & $\begin{array}{l}893 \\
446 \\
216\end{array}$ \\
\hline $\begin{array}{l}\text { ote: Table presents results of a } \\
\text { tition round. Columns (1) an } \\
\text { olumns (3) and (4) the ATET } \\
\text { servation is a startup in a comp } \\
10 \%, 5 \% \text {, and } 1 \% \text { levels, respe }\end{array}$ & $\begin{array}{l}\text { Copensity scor } \\
\text { (2) display tl } \\
\text { verage Treatn } \\
\text { ition round. *, } \\
\text { ively }\end{array}$ & $\begin{array}{l}\text { e matching. } \\
\text { he ATE (Avt } \\
\text { hent Effect o } \\
* * \text {, and } * * *\end{array}$ & $\begin{array}{l}\text { rrors are clust } \\
\text { age Treatmen } \\
\text { the Treated). } \\
\text { enote statistic }\end{array}$ & $\begin{array}{l}\text { ered by com- } \\
\text { Effect) and } \\
\text { The level of } \\
\text { a significance }\end{array}$ \\
\hline
\end{tabular}

We have shown that our findings hold when using alternative specifications. Stage 1 is the only stage in which a win has a significant and consistent positive effect on the future performance of participating startups. We argue that this finding provides support for Proposition 1. The main benefit that comes from participating in Venture Kick most likely resides in the signal of quality that the competition provides to its participants.

\subsection{Investigating Venture Kick's certification effect}

To increase the robustness of our claim that it is indeed certification that matters most we delve deeper into the mechanisms at play. We do so by examining the predictions from our model that support Proposition 1, namely Lemma 1.a and 1.b. 


\section{Entrepreneurs react more strongly to a negative certification than a positive one.}

In order to investigate the effect that Venture Kick's certification of quality has on entrepreneurs' decision-making, we use survival rates. Looking at them we can investigate whether, as expected, the certification effect is concentrated on losing startups' founders. Remember that stage 1 of the competition is usually the first time that entrepreneurs receive an objective assessment of their startup's quality from multiple experts. This assessment provides entrepreneurs with valuable information about their startup's probability of future success. Consequently we would expect losing startups to have lower survival rates than they would have had if they had not participated in the competition. Their poor performance in Venture Kick informs them that their venture might not have as much potential as they had anticipated. On the other hand, winning startups get confirmation that their venture shows promise but it is less clear whether their survival rates should be significantly higher than non-participating startups as a result.

We can test the claim that the impact of Venture Kick on survival is concentrated on losing startups by comparing the survival rates of startups in our sample with the typical survival rates of young Swiss or American ventures. The Swiss Federal Statistical Office (FSO) and the U.S. Bureau of Labor Statistics (BLS) provide these figures. They calculated that, in the past decade, the survival rate of startups two years after birth has been around 67-70 percent, 60 percent after three years, then 54 percent and finally 50 percent after five years. ${ }^{25}$ For Venture Kick's participants, these numbers are respectively $61,58,55$ and 52 percent. In other words, in the short term, startups that participate in the competition have lower survival rates than typical young companies but then after four years they start having slightly higher survival rates than typical startups. Additionally, we use the model in Table 3 to predict the survival rate of a startup of average quality as a function of whether it wins or loses stage 1. For winning startups, the predicted survival rate after 2 years is 0.69 , very close to the FSO value for the average young Swiss company. The predicted survival rate for losing startups reaches 0.48 , more than 22 percentage points below the average survival rate in Switzerland. Taken together, these elements support Lemma 1.a: it seems that losers will cut their losses much quicker than they would have otherwise, thus avoiding costly wastage of resources Given that this effect of Venture Kick's certification of quality on survival rates seems to be focused on

\footnotetext{
${ }^{25}$ These statistics are available on the FSO's website: https://www.bfs.admin.ch/bfs/.../taux-desurvie.assetdetail.10687119.html and the BLS's: https://www.bls.gov/bdm/us_age_naics_00_table7.txt
} 
the losers, it makes sense that it is only the performance in stage 1 that causally impacts survival. Indeed, losing in stages 2 and 3 will only happen after having won stage 1 and received praise for their quality. Losing in these later stages should thus not cause entrepreneurs to drastically rethink their probability of success.

\section{Marginal startups are most affected by certification.}

If Venture Kick's certification does indeed provide an informative signal of quality to outside investors, its positive effect should be strongest for marginal winners whose quality is less apparent. Indeed, marginal winners should particularly benefit from a certification of their quality, because it might represent the extra information needed for both entrepreneurs and investors to decide to pursue or invest in a startup. We find evidence that this mechanism is at play. We observe that the startups that benefit most from winning the first stage - and thus from Venture Kick's certification effect - are those that win while receiving relatively low grades. To compute this treatment effect conditional on startup quality we compute Equation 1 using a logistical regression. Figure G.1 in Appendix $G$ shows that it is the startups around the third grade decile (with a standardized grade of -0.53 ) that benefit most from winning stage 1 . This finding is in line with Howell (2019), who finds that her competitions' signal of quality is impactful for marginal ventures that are not an obviously profitable investment. Similarly, Cao (2018) finds that Product Hunt, a website that curates the best products and ideas, is particularly useful in helping disadvantaged founders (less experience, less well located) to get access to venture capital funds.

The results presented in this section provide evidence that winning in a venture competition is mainly useful because it provides startups with a respected certification of their quality. This certification will be used by founders to inform them about their probability of success, causing losing startups to stop their activity quicker than they would have otherwise. This certification will also be used by winning startups as proof of their quality to outside investors, improving their funding prospects. It is also stronger for marginal startups.

\section{Testing Prediction 2: Technology Heterogeneity}

Results in Section 6 are average effects over the sample. As such, they conceal the fact that Venture Kick might have a heterogeneous effect on participating startups. We 
therefore now turn to testing Proposition 2: Venture competitions have a heterogeneous effect on participating startups, depending on their technology type. We showed in Section 5 that judges were not consistent across sectors in their ability to differentiate between high- and low-quality startups. We predict that these sector-related differences will affect the certification effect. Lemma 2.a states that certification is more useful to startups in sectors that experts' are adept at screening. Indeed, the value attributed to Venture Kick's certification of low_info startups should be smaller, knowing that it is harder for judges to predict which one will become a success. Additionally, while we have shown in Section 6.1 that the cash prize does not seem to have an impact on average, we expect it to have a heterogeneous effect depending on the recipient startup's technology. We predict in Lemma 2.b that the cash prize's effect is concentrated on startups with low running costs.

In order to test these technology-related predictions we separate our data into two technology groups: the science-based startups and the ICT startups. We use sciencebased and ICT startups to identify respectively the impact of the competition on high_info and low_info startups. We are able to do so because both our data and Scott et al. (2020) find that venture competitions' judges are relatively more adept at screening science-based startups. This separation in two technology groups also allows us to look into the impact of the competition on startups of varying running costs. Science-based startups typically require significant capital investments while ICT startups have lower costs, in part because they have recently benefited from technological shocks (e.g. the advent of cloud computing) that have significantly reduced the cost of running a business in these sectors (Ewens et al., 2018). We therefore simplify our model to only two broad technology types because they already provide the necessary variability to the parameters that matter: running costs and experts' ability to predict the startup future success.

In this section we adapt Equation (1) to capture a differentiated treatment effect between ICT startups and the more science-based startups in the competition, which allows us to test Lemma 2.a and 2.b.

$$
\begin{aligned}
Y_{i}^{\text {Hetero }}= & \alpha_{i, s}+\delta_{1} \text { WinsStage }_{i, s}+\delta_{2} \text { WinsStage }_{i, s} * I C T_{i}+\beta_{1} \text { StartupQuality }_{i, s} \\
& +\beta_{2} I C T_{i}+\beta_{3} \text { StartupQuality }_{i, s} * I C T_{i}+\gamma_{\text {year } / \text { comp } / \text { uni }}+\epsilon_{i, s}
\end{aligned}
$$

We now allow for a different effect of winning each stage between sectors $\left(\delta_{2}\right)$ and a different relationship between judges' grades and future outcomes $\left(\beta_{3}\right) . \delta_{1}$ is now the effect of winning a given stage for science-based startups. 


\subsection{The heterogeneous effect of Venture Kick}

To facilitate the comparison across sectors we mainly use figures in this section rather than regression tables to show the effects. While we do not display sample size, remember that 43 percent of startups in our sample are categorized as being ICT. Figures 4 and 5 show the effect of winning each stage of the competition using Equation 2 for our two broad technology categories.

Figure 4: Effect of winning stages 1,2 and 3 on survival for two broad technology categories

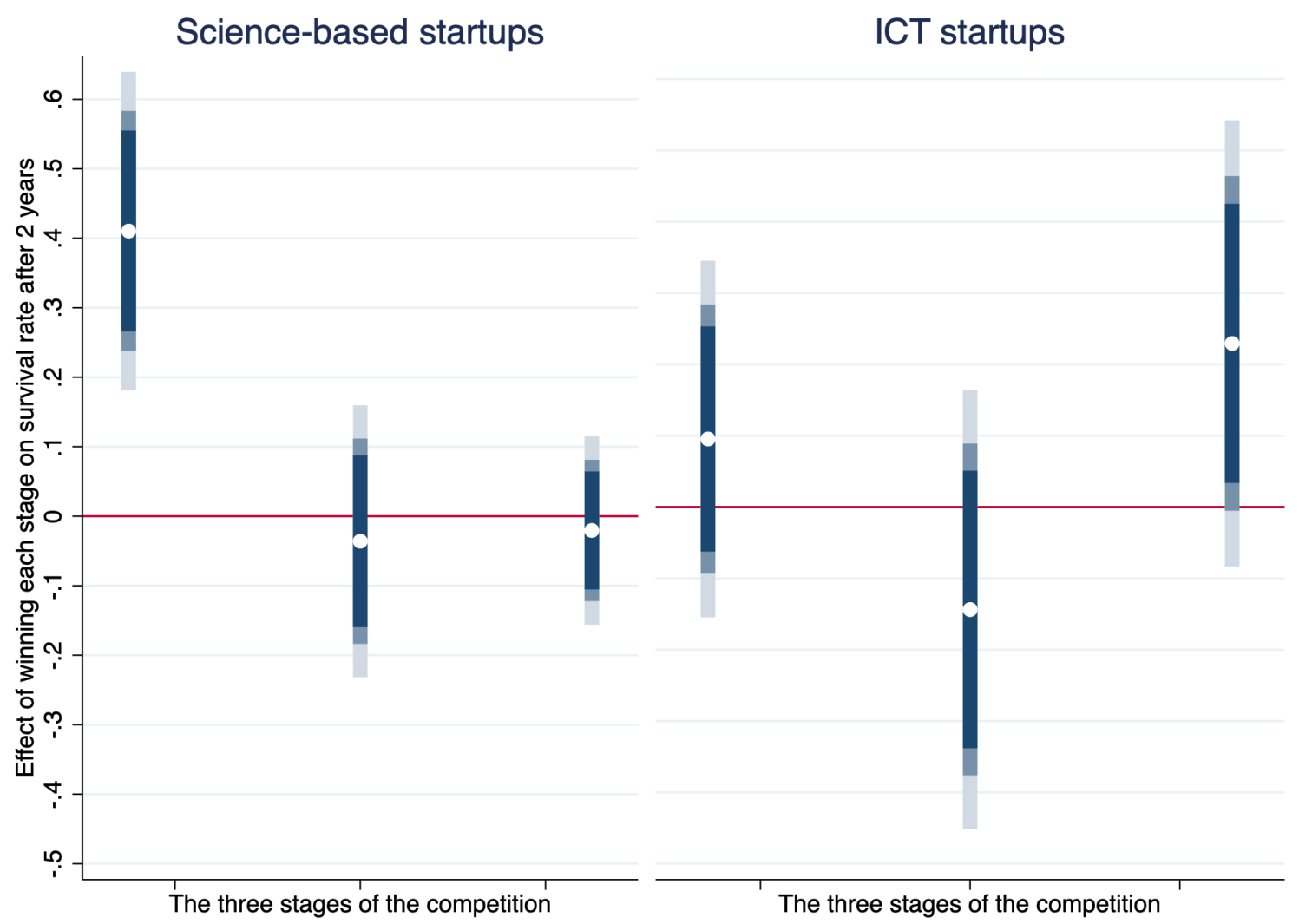

Note: This figure presents the effect of winning stage 1 on Survival 2 for both science-based and ICT startups using Equation 2. Errors are clustered by competition round. The confidence intervals are at the $10 \%, 5 \%$ and $1 \%$ levels, respectively.

As we hypothesized, these results show that Venture Kick has a significantly different impact on startups, depending on their technology type. ${ }^{26}$ On the one hand, for sciencebased startups we find once more that Venture Kick mostly helps by providing a trusted

${ }^{26}$ For the actual statistical test of this differential effect please refer to Table 7 , which shows in Columns (1) and (4) that winning has a significantly different impact on ICT and science-based startups. 
Figure 5: Effect of winning stages 1, 2 and 3 on funding for two broad technology categories
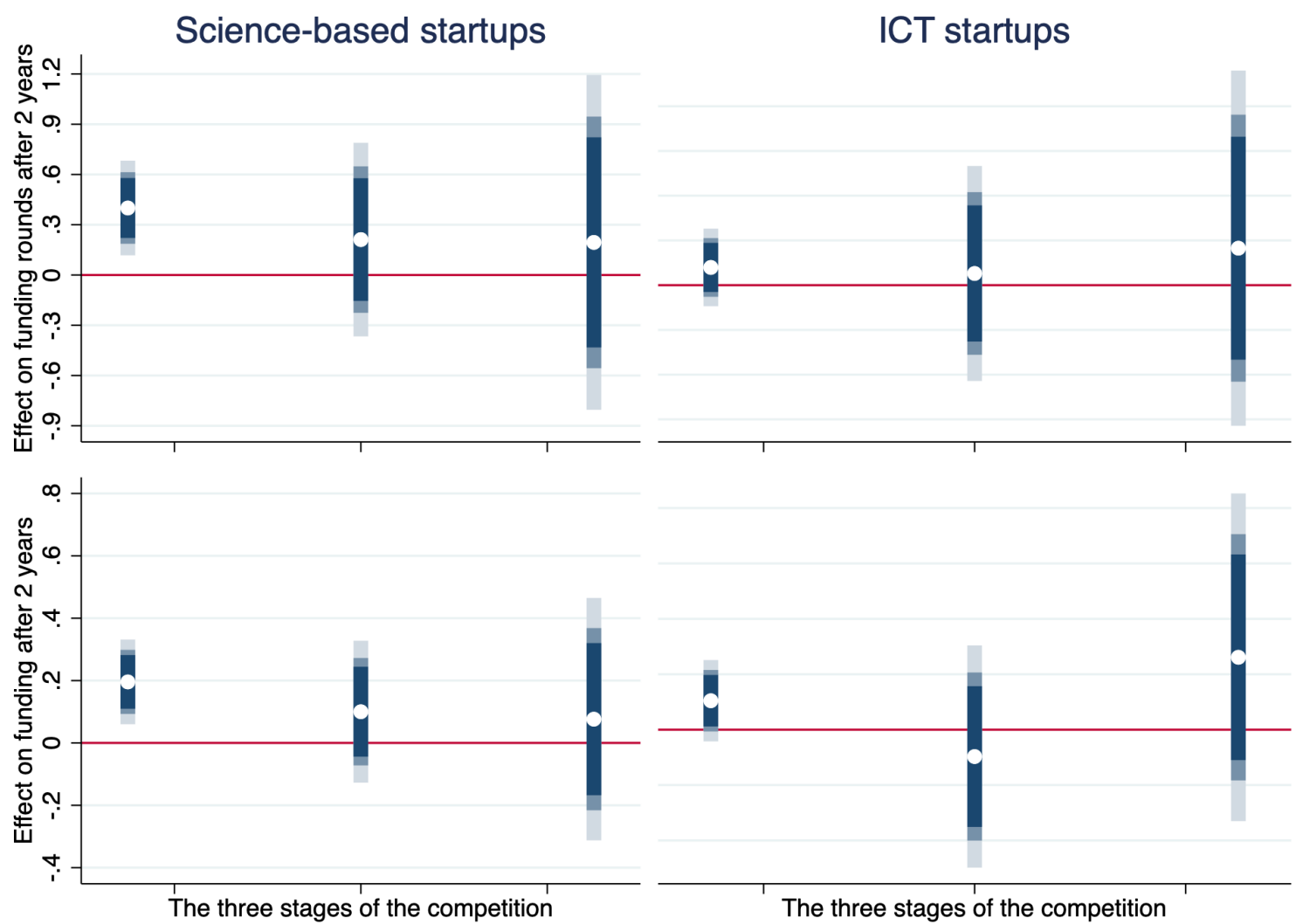

Note: This figure presents the effect of winning stage 1 on Rounds 2 on the top panel and on Funding 2 in the bottom panel for both science-based and ICT startups using Equation 2. Errors are clustered by competition round. The confidence intervals are at the 10\%, 5\% and $1 \%$ levels, respectively.

certification of their quality to both founders and outside investors. Indeed, winning stage 1 increases the survival rate two years after the competition by 41 percentage points. It also causes the expected number of funding rounds secured to rise by 0.4 and the probability of securing funding by 20 percentage points. Moreover, winning stage 3 and receiving the cash prize does not have any impact. This is understandable given that $\$ 100,000$ will not sustain a science startup very long and that investors should not be affected by the cash prize. On the other hand, we see that none of Venture Kick's stages have an impact on ICT startups' funding outcomes. ${ }^{27}$ Additionally, unlike science startups, winning stages 1 and 2 does not have any impact on their survival rates. This

${ }^{27}$ While stage 1 seems to have an impact at the 10 percent significance level when Funding 2 is used as the outcome variable, this effect disappears entirely with all the other financing variables. 
result that Venture Kick's stages 1 and 2 have no effect on ICT startups is evidence that supports Lemma 2.a. Indeed, because the certification does not provide entrepreneurs and investors with very reliable information about the startup's probability of success, it does not impact either survival rates or funding.

We also find that ICT ventures are the only ones whose survival rates benefit from winning the last stage of Venture Kick. Winning stage 3 and the related $\$ 100,000$ prize increases the survival rate of ICT ventures two years after the competition by 23 percentage points. ${ }^{28}$ However, as indicated in Figure 6, this effect is short-lived, having no long-term effect on survival or funding outcomes. The fact that winning stage 3 never has any significant impact on funding outcomes regardless of the specification used is further evidence that a cash prize does not affect investors' assessments of a startup's value, as we assume in our model. The impact of the cash prize is therefore limited to allowing some of its weakest recipients to survive a couple more years than they would have without it, with no real improvement in startups' prospects. This finding provides evidence in favour of Lemma 2.b. While we attribute the particular effect of the cash prize on ICT startups to their lower running cost, it could also result from Venture Kick's weak certification of their quality. Indeed, because it is harder to assess their potential, ICT ventures might face higher financing constraints, which makes Venture Kick's money all the more valuable.

The fact that judges are less adept at screening ICT startups provides interesting variability in the data, which we exploit to study the impact of Venture Kick on high_info versus low_info startups. However, it also makes grades a less accurate proxy of ICT startups' quality, potentially threatening our identification strategy. To address this concern we first the RDD and PSM approaches described in Section 6.2, both of which are less reliant on using a proxy to control for startup quality. Table H.1 in Appendix H shows that our results are robust to using an RDD, if anything stage 1 has now even less impact on ICT startups' funding outcomes. Table H.2 presents the result of a propensity score matching that confirms that only stage 3 has an impact on ICT startups. To further test the validity of our findings, we use an errors-in-variables regression, as we did in Section 6.2, in which we allow ICT startups' grading to be 20 percent less reliable than science startups'. Comparing Columns (2) and (3) as well as Columns (5) and (6) of Table 7 shows that assuming more imprecision in ICT grading does not contradict our results, on the contrary, it becomes even clearer that winning stage 1 has no effect on ICT

\footnotetext{
${ }^{28}$ This effect is not enough to cause a positive average effect because while ICT startups represent 43 percent of our sample, they only represent 17 percent of the stage 3 winners.
} 
Figure 6: Effect of winning stages 1 and 3 on survival over the years for two broad technology categories

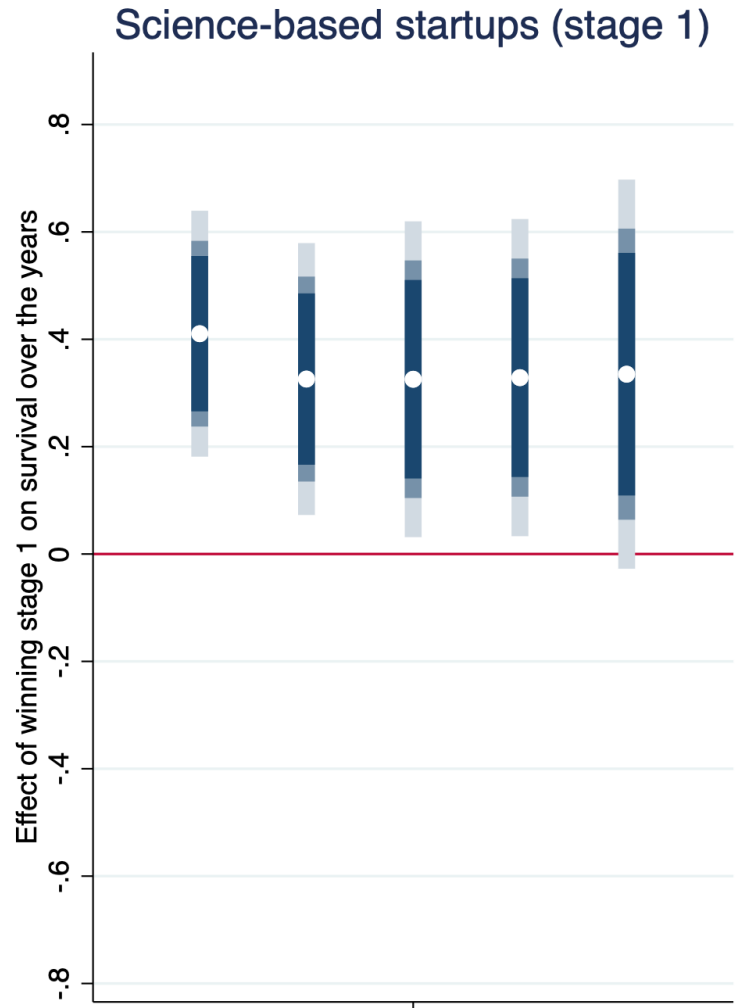

Two to six years after the competition

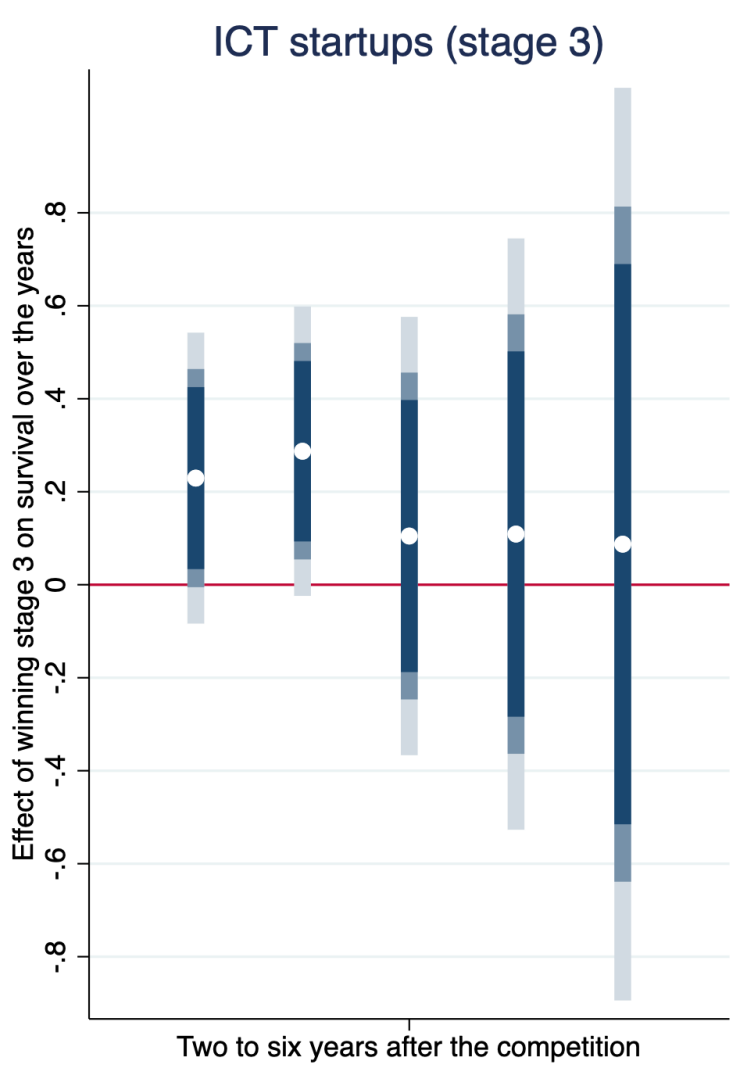

Two to six years after the competition

Note: This figure presents the effect of winning stage 1 on Survival 2 for science-based startups and the effect of winning stage 3 for ICT startups, two to six years after the competition using Equation 2. Errors are clustered by competition round. The confidence intervals are at the $10 \%, 5 \%$ and $1 \%$ levels, respectively.

startups. Using the same approach our results for stage 3 also hold, only ICT startups benefit from winning the final stage. Columns (1) and (4) provide confirmation that the competition has a statistically significant differential effect on startups depending on their technology type; winning stage 1 increases the survival rate of science-based startups two years after the competition by 31.5 percentage points more than ICT startups'

In conclusion, we find evidence to support the second prediction of our model that Venture Kick has a heterogeneous effect on participating startups. For science-based startups, winning stage 1 results in an increase in both their survival rates and external funding after the competition. However, winning the last two stages does not seem to have any impact. We argue that these results indicate that science-based startups, whose quality is assessed with greater precision by the competition's judges, benefit greatly 
Table 7: Effect of winning stage 1 using an errors-in-variables regression

\begin{tabular}{|c|c|c|c|c|c|c|}
\hline & \multicolumn{2}{|c|}{ Baseline } & \multirow{2}{*}{$\frac{\mathrm{EiV}}{(3)} \frac{(3)}{\text { Survival } 2}$} & \multicolumn{2}{|c|}{ Baseline } & \multirow{2}{*}{$\frac{\mathrm{EiV}}{(6)} \frac{}{\text { Survival } 2}$} \\
\hline & $\begin{array}{c}(1) \\
\text { Survival } 2\end{array}$ & $\begin{array}{c}(2) \\
\text { Survival } 2\end{array}$ & & $\begin{array}{c}(4) \\
\text { Survival } 2\end{array}$ & $\begin{array}{c}(5) \\
\text { Survival } 2\end{array}$ & \\
\hline Wins Stage 1 & $\begin{array}{l}0.410^{* * *} \\
(0.0870)\end{array}$ & $\begin{array}{l}0.499^{* * *} \\
(0.0601)\end{array}$ & $\begin{array}{l}0.512^{* * *} \\
(0.0959)\end{array}$ & $\begin{array}{c}0.0953 \\
(0.0950)\end{array}$ & $\begin{array}{l}0.176^{* * *} \\
(0.0677)\end{array}$ & $\begin{array}{l}-0.283 \\
(0.394)\end{array}$ \\
\hline Standardized grade & $\begin{array}{l}0.137^{* * *} \\
(0.0404)\end{array}$ & $\begin{array}{l}0.0558^{*} \\
(0.0295)\end{array}$ & $\begin{array}{c}0.0459 \\
(0.0617)\end{array}$ & $\begin{array}{c}0.121^{* *} \\
(0.0487)\end{array}$ & $\begin{array}{l}0.0665^{* *} \\
(0.0334)\end{array}$ & $\begin{array}{c}0.399 \\
(0.281)\end{array}$ \\
\hline Wins $\mathrm{x}$ ICT & $\begin{array}{c}-0.315^{* *} \\
(0.123)\end{array}$ & $\begin{array}{c}-0.323^{* * *} \\
(0.0905)\end{array}$ & $\begin{array}{l}-0.354^{*} \\
(0.210)\end{array}$ & & & \\
\hline Internet \& Software & $\begin{array}{c}0.142^{*} \\
(0.0792)\end{array}$ & $\begin{array}{c}0.135^{* *} \\
(0.0598)\end{array}$ & $\begin{array}{c}0.152 \\
(0.122)\end{array}$ & & & \\
\hline Grade x ICT & $\begin{array}{l}-0.0155 \\
(0.0571)\end{array}$ & $\begin{array}{c}0.0107 \\
(0.0445)\end{array}$ & $\begin{array}{l}0.0333 \\
(0.143)\end{array}$ & & & \\
\hline Wins x Science & & & & $\begin{array}{l}0.315^{* *} \\
(0.123)\end{array}$ & $\begin{array}{l}0.323^{* * *} \\
(0.0905)\end{array}$ & $\begin{array}{l}0.782^{*} \\
(0.400)\end{array}$ \\
\hline Science & & & & $\begin{array}{l}-0.142^{*} \\
(0.0792)\end{array}$ & $\begin{array}{l}-0.135^{* *} \\
(0.0598)\end{array}$ & $\begin{array}{l}-0.419^{*} \\
(0.247)\end{array}$ \\
\hline Grade x Science & & & & $\begin{array}{c}0.0155 \\
(0.0571)\end{array}$ & $\begin{array}{l}-0.0107 \\
(0.0445)\end{array}$ & $\begin{array}{l}-0.343 \\
(0.283)\end{array}$ \\
\hline Year FE & Yes & No & No & Yes & No & No \\
\hline Competition FE & Yes & No & No & Yes & No & No \\
\hline University FE & Yes & No & No & Yes & No & No \\
\hline $\begin{array}{l}\text { Observations } \\
R^{2}\end{array}$ & $\begin{array}{c}671 \\
0.380\end{array}$ & $\begin{array}{c}671 \\
0.231\end{array}$ & $\begin{array}{c}671 \\
0.231\end{array}$ & $\begin{array}{c}671 \\
0.380\end{array}$ & $\begin{array}{c}671 \\
0.231\end{array}$ & $\begin{array}{c}671 \\
0.254\end{array}$ \\
\hline
\end{tabular}

Note: This table presents results of standard as well as errors-in-variables regressions. In Columns (1) to (3), the coefficient on the Wins Stage 1 variable can be interpreted as the effect of winning stage 1 for science startups, while its coefficients in Columns (4) to (6) can be interpreted as the effect of winning stage 1 for ICT startups. Columns (1) and (4) report our baseline specification, Equation 2 or the regressions behind Figure 4. Columns (2) and (4) are standard regressions without fixed effects which serves as a benchmark for Columns (3) and (6), that show our errors-in-variables regressions with, respectively, the ICT grade interaction and the ICT grade variables having a reliability of 0.8 . The grades attributed to science startups are assumed to be reliable. The level of observation is a startup in a competition round. Errors are clustered by competition round in columns (1) and $(4) . * * *$, and $* * *$ denote statistical significance at $10 \%, 5 \%$, and $1 \%$ levels, respectively.

from Venture Kick's certification. For harder-to-assess ICT startups, however, we find no evidence that winning Venture Kick's early stages provides any benefit, a sign that certification is not that helpful. We nevertheless find that for these startups, winning the whole competition and the $\$ 100,000$ cash prize causes an increase in survival rates during the two to three years that follow the event. Subsequently, however, there is no sign that the cash prize has any impact on startups' survival. 


\section{Concluding Remarks}

Changes in the cost of starting a venture have lowered the barriers to entrepreneurship. One consequence of this development is that it has become more difficult for investors to search for and identify the most promising startups. This increased information asymmetry can weigh on investments. In this context, new financial intermediaries like venture competitions can be useful complements to venture capital in stimulating innovation and entrepreneurship. Indeed, they offer an evaluation and certification of startups' quality at a low cost. This certification, if accurate, can in turn help reduce the time required for investors to efficiently screen early-stage ventures.

In this paper, we propose a model to better understand how venture competitions impact participating startups and test its predictions on a sample of 987 startups that have participated in Venture Kick, the leading Swiss venture competition. We find that venture competitions like Venture Kick can provide significant benefits to participating startups. The positive effect of our venture competition is, however, concentrated in its first stage, where most of the certification happens. We argue that this result is evidence that venture competitions are mostly helpful because they certify startups' quality and not because they offer cash prizes. This certification provides valuable information to both entrepreneurs and outside investors, which accelerates the termination of low-quality startups and improves external funding opportunities for high-quality startups.

We also find that venture competitions have a sector-specific impact on startup performances. For startups with high running costs and whose quality can be assessed more objectively, such as science-based startups, our average causal impact holds. Obtaining certification by winning Venture Kick's first stage has a significant positive impact on science-based startups' long-term prospects while winning the third stage and its cash prize has no significant impact. By contrast, startups with low running costs and whose quality is harder to assess, such as ICT startups, do not seem to benefit from Venture Kick's certification but do benefit from winning the $\$ 100,000$ prize. However, this cash prize effect is short-lived, increasing ICT startups' short-term survival rate without affecting these startups' long-term success.

We contend that the heterogeneity of effects arises from differences in the quality of judges' ratings and startup running costs. Because Venture Kick's experts are less objective when assessing the quality of ICT startups, their certification is less informative to both entrepreneurs and investors. We argue, therefore, that a venture competition's certification is only valuable if its judges are able to reliably assess the startups' probabil- 
ity of success. Additionally, we argue that the cash prize effect depends on the recipient startup's running costs. In countries with a vibrant entrepreneurial finance sector such as the United States or Switzerland, promising startups should be able to secure external financing if the need arises. In this context, the cash prize's main effect is to allow less viable startups to survive a few more periods than they would have been able to otherwise. As a result, the cash prize is particularly helpful to the startups with low running costs that allow them to survive longer on the prize alone. These new findings highlight sector-specific heterogeneity in startups early-stage support needs, which bears implications for the design of entrepreneurial programs. 


\section{References}

Amit, R., L. Glosten, And E. Muller (1990): "Entrepreneurial ability, venture investments, and risk sharing," Management science, 36, 1233-1246.

Angrist, J. D. (2001): "Estimation of Limited Dependent Variable Models With Dummy Endogenous Regressors," Journal of Business $\& 3$ Economic Statistics, 19, 2-28.

Arrow, K. J. (1971): "The economic implications of learning by doing," in Readings in the Theory of Growth, Springer, 131-149.

Åstebro, T. And Y. GerchaK (2001): "Profitable advice: The value of information provided by Canada's inventor's assistance program," Economics of Innovation and New Technology, 10, 45-72.

Bernstein, S., A. Korteweg, and K. Laws (2017): "Attracting Early-Stage Investors: Evidence from a Randomized Field Experiment," Journal of Finance, 72, 509-538.

CAO, R. (2018): "Information Frictions in New Venture Finance: Evidence from Product Hunt Rankings," Working Paper.

Carpenter, R. E. And B. C. Petersen (2002): "Is the growth of small firms constrained by internal finance?" The Review of Economics and Statistics, 84, 298-309.

Clementi, G. L. And H. A. Hopenhayn (2006): "A theory of financing constraints and firm dynamics," Quarterly Journal of Economics, 121, 229-265.

Clingingsmith, D. And S. Shane (2017): "Let Others Go First : How Pitch Order Affects Investor Interest in Elevator Pitches," 1-33.

Connelly, B. L., L. Tihanyi, T. R. Crook, and K. A. Gangloff (2014): "Tournament Theory: Thirty Years of Contests and Competitions," Journal of Management, $40,16-47$.

Ewens, M., R. NAnda, And M. Rhodes-Kropf (2018): "Cost of experimentation and the evolution of venture capital," Journal of Financial Economics, 128, 422-442.

Gompers, P. A., W. Gornall, S. N. Kaplan, and I. A. Strebulaev (2020): "How do venture capitalists make decisions?" Journal of Financial Economics, 135, 169-190. 
Hellmann, T. And M. Puri (2002): "Venture Capital and the Professionalization of Start-Up Firms: Empirical Evidence," The Journal of Finance, LVII, 169-197.

Hildebrand, T., M. Puri, And J. Rocholl (2017): "Adverse Incentives in Crowdfunding," Management Science, 63, 587-608.

HochberG, Y. V. (2016): "Accelerating entrepreneurs and ecosystems: The seed accelerator model," Innovation Policy and the Economy, 16, 25-51.

HochberG, Y. V. And D. C. Fehder (2014): "Accelerators and the Regional Supply of Venture Capital Investment," Available at SSRN 2518668, 1-40.

Holtz-Eakin, D., D. Joulfaian, And H. S. Rosen (1994): "Sticking it Out: Entrepreneurial Survival and Liquidity Constraints," Journal of Political Economy, 102, $53-75$.

HowelL, S. T. (2017): "Financing Innovation : Evidence from R\&D Grants," American Economic Review, 107, 1136-1164.

(2019): "Reducing Information Frictions in Venture Capital: The Role of New Venture Competitions," Journal of Financial Economics.

KAPlan, S. N. AND J. LeRner (2010): "It ain't broke: The past, present, and future of venture capital." Journal of Applied Corporate Finance, 22, 36-47.

Kaplan, S. N., B. A. Sensoy, and P. Stromberg (2009): "Should Investors Bet on the Jockey or the Horse? Evidence from the Evolution of Firms from Early Business Plans to Public Companies," The Journal of Finance, 64, 75-115.

Kerr, W. R., J. Lerner, And A. Schoar (2011): "The Consequences of Entrepreneurial Finance : Evidence from Angel Financings," The Review of Financial Studies, 20-55.

Koellinger, P., M. Minniti, And C. Schade (2007): “"I think I can, I think I can": Overconfidence and entrepreneurial behavior," Journal of Economic Psychology, 28, $502-527$.

Lerner, J., A. Schoar, S. Sokolinski, and K. Wilson (2018): "The globalization of angel investments: Evidence across countries," Journal of Financial Economics, 127, $1-20$. 
MCCRARY, J. (2008): "Manipulation of the running variable in the regression discontinuity design: A density test," Journal of Econometrics, 142, 698-714.

MCKenzIE, D. (2017): "Identifying and spurring high-growth entrepreneurship: Experimental evidence from a business plan competition," American Economic Review, 107, $2278-2307$.

Minniti, M. And W. Bygrave (2001): "A dynamic model of entrepreneurial learning," Entrepreneurship theory and practice, 25, 5-16.

Mollick, E. (2014): "The dynamics of crowdfunding: An exploratory study," Journal of Business Venturing, 29, 1-16.

NAnda, R. And M. Rhodes-Kropf (2016): "Financing entrepreneurial experimentation," Innovation Policy and the Economy, 16, 1-23.

Scott, E. L., P. Shu, And R. M. Lubynsky (2020): "Entrepreneurial uncertainty and expert evaluation: An empirical analysis," Management Science, 66, 1278-1299.

Smith, B. And A. Viceisza (2018): "Bite me! ABC's Shark Tank as a path to entrepreneurship," Small Business Economics, 50, 463-479.

Timmons, J. A. And W. D. Bygrave (1986): "Venture capital's role in financing innovation for economic growth," Journal of Business Venturing, 1, 161-176.

Venture Kick (2019): "Annual Report," 1-28.

Yu, S. (2019): "How Do Accelerators Impact the Performance of High-Technology Ventures?" Management Science. 
A Appendix A: Venture Kick's grading categories in detail

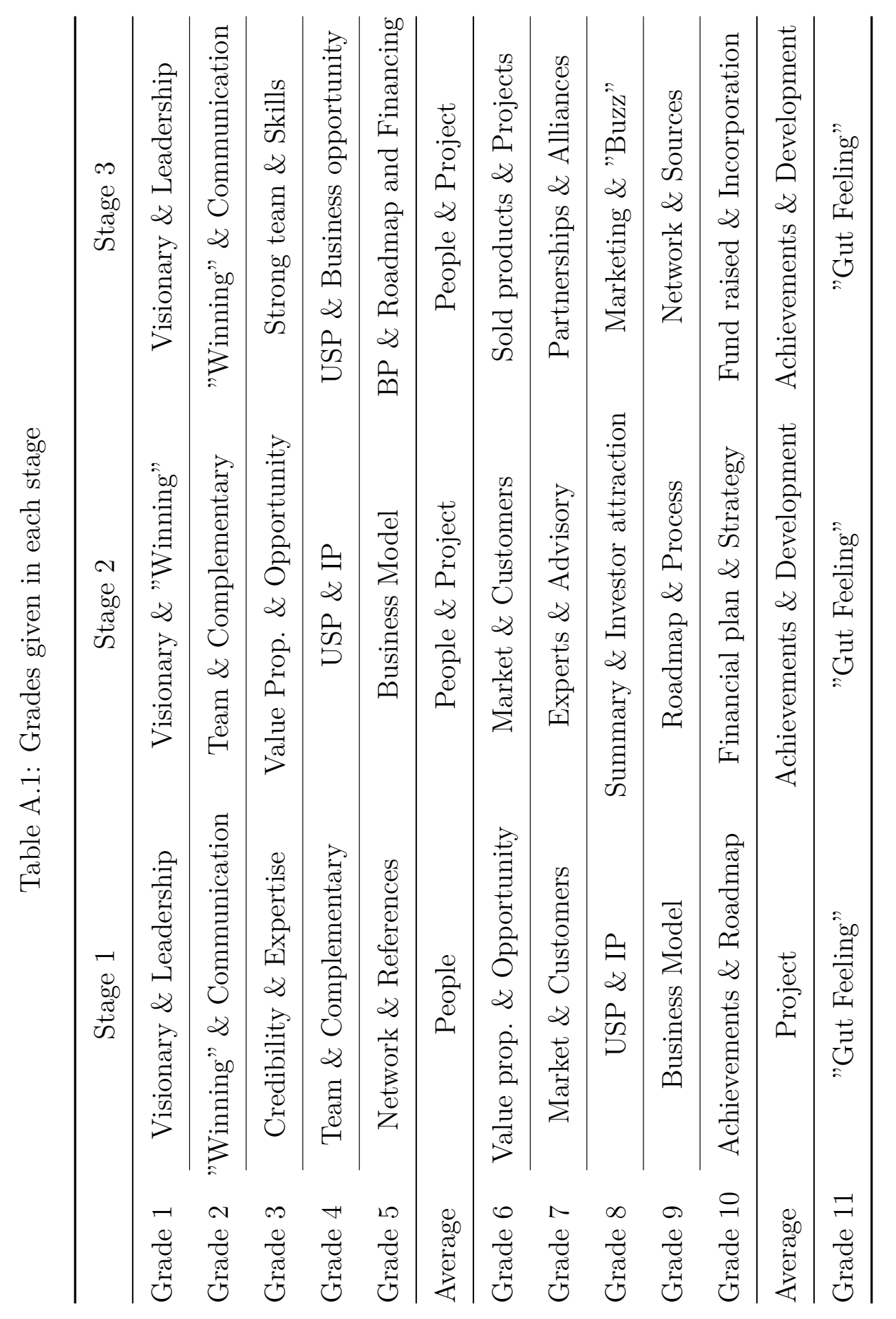




\section{B Appendix B: Venture Kick's publicity}

\section{B.1 Venture Kick is a respected institution}

Venture Kick's publicity is valuable because it originates from a trusted institution. These are endorsements from a member of Switzerland's largest private science and innovation foundation and a member of Swisscom, Switzerland's biggest telecom company :

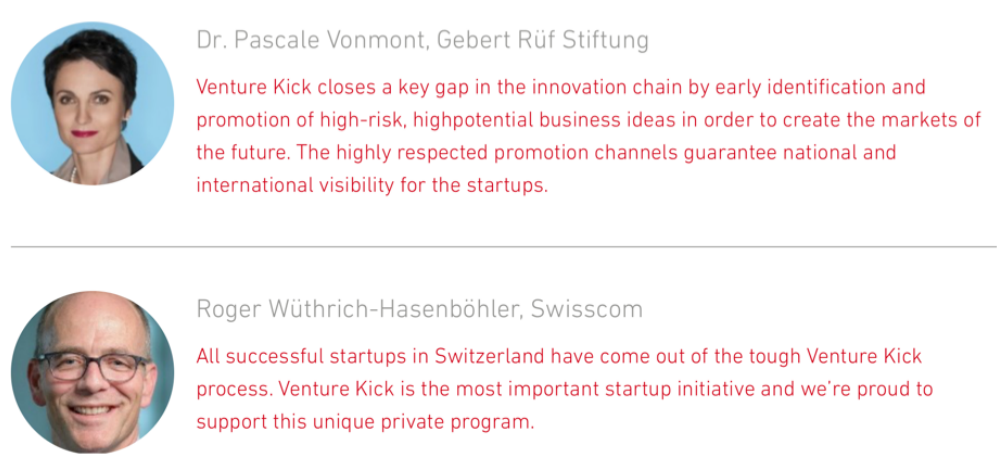

Source: Venture Kick's website

\section{B.2 The case of Imverse: a startup that won stage 1 in 2017}

\section{B.2.1 Venture Kick's article}

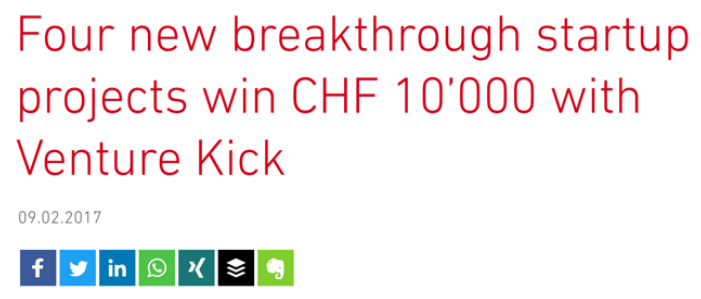

\section{$f|y|$ in $|0| x \mid \Xi$ क}

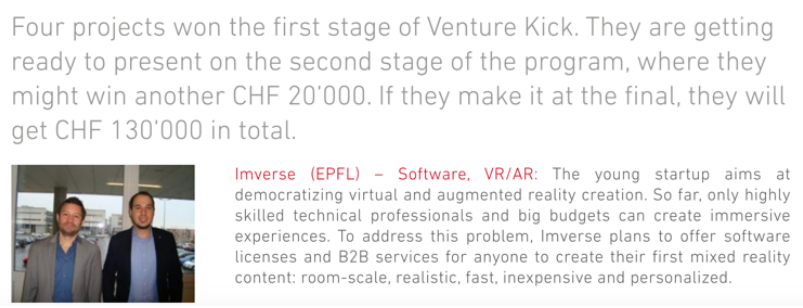

Source: Venture Kick's website 


\section{B.2.2 Venture Kick's tweet}

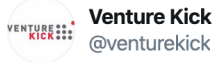

Four startup projects win their first $\mathrm{CHF} 10^{\prime} 000$ with

Venture Kick: Imverse, Gnubiotics, InstaHeat and

Triplequote bit.ly/2km8pAP

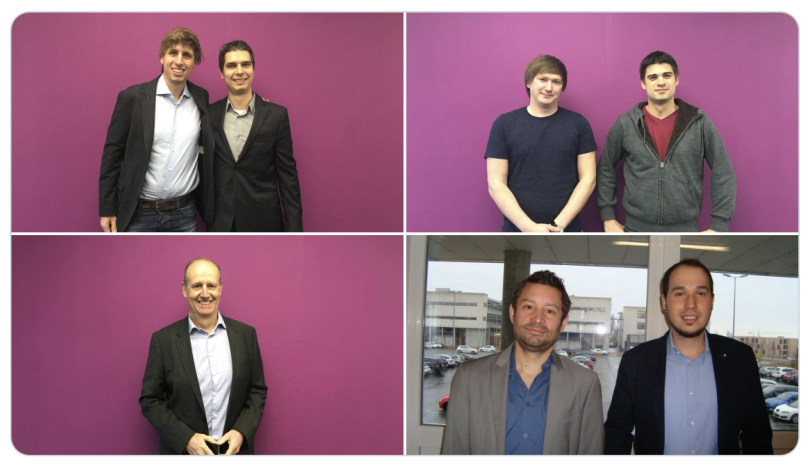

Source: Twitter

B.2.3 Venture Kick's logo on Imverse's website

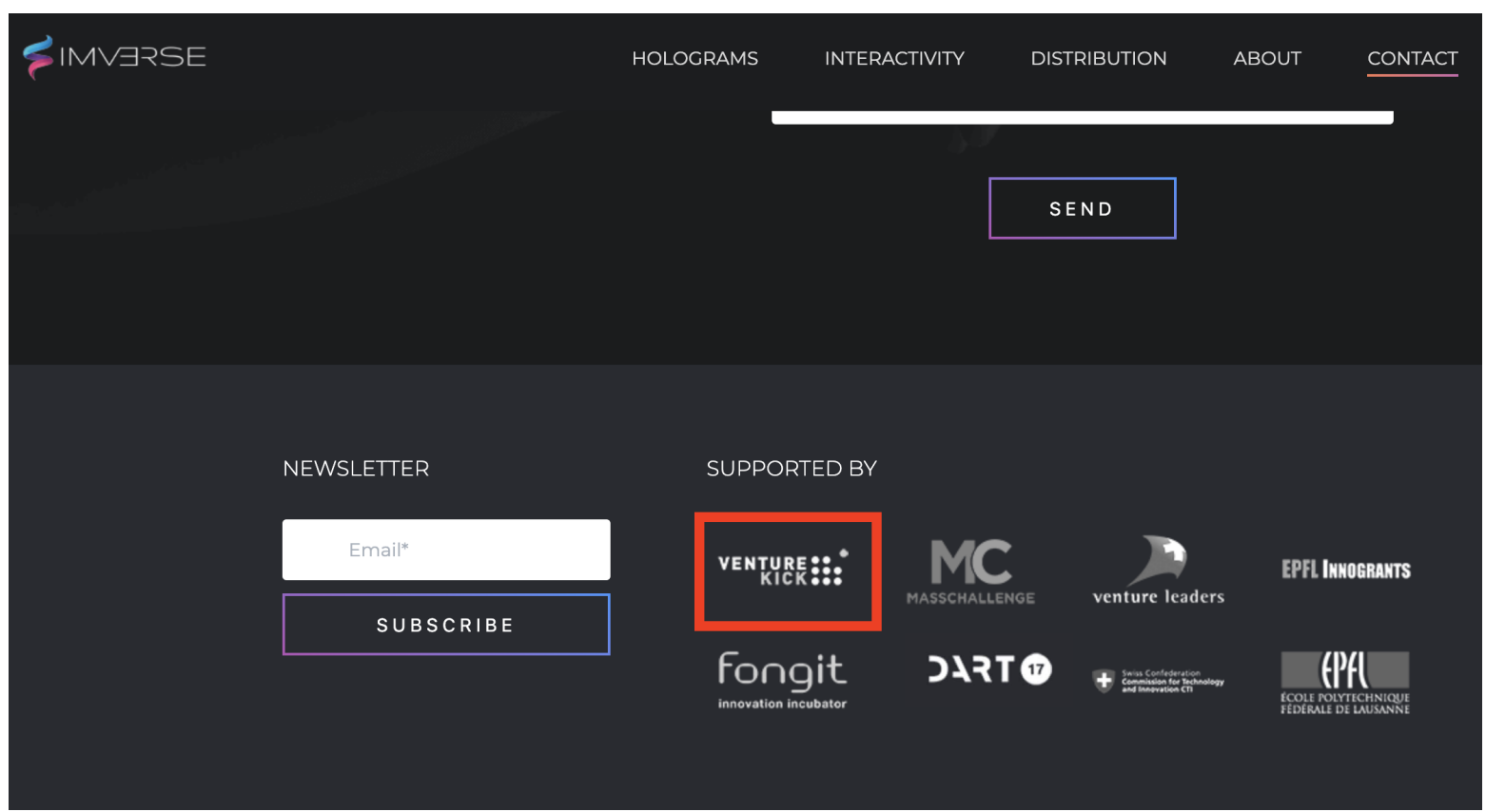

Source: Imverse's website 


\section{Appendix C: The Venture Kick process}

Figure C.1: The three stages of Venture Kick

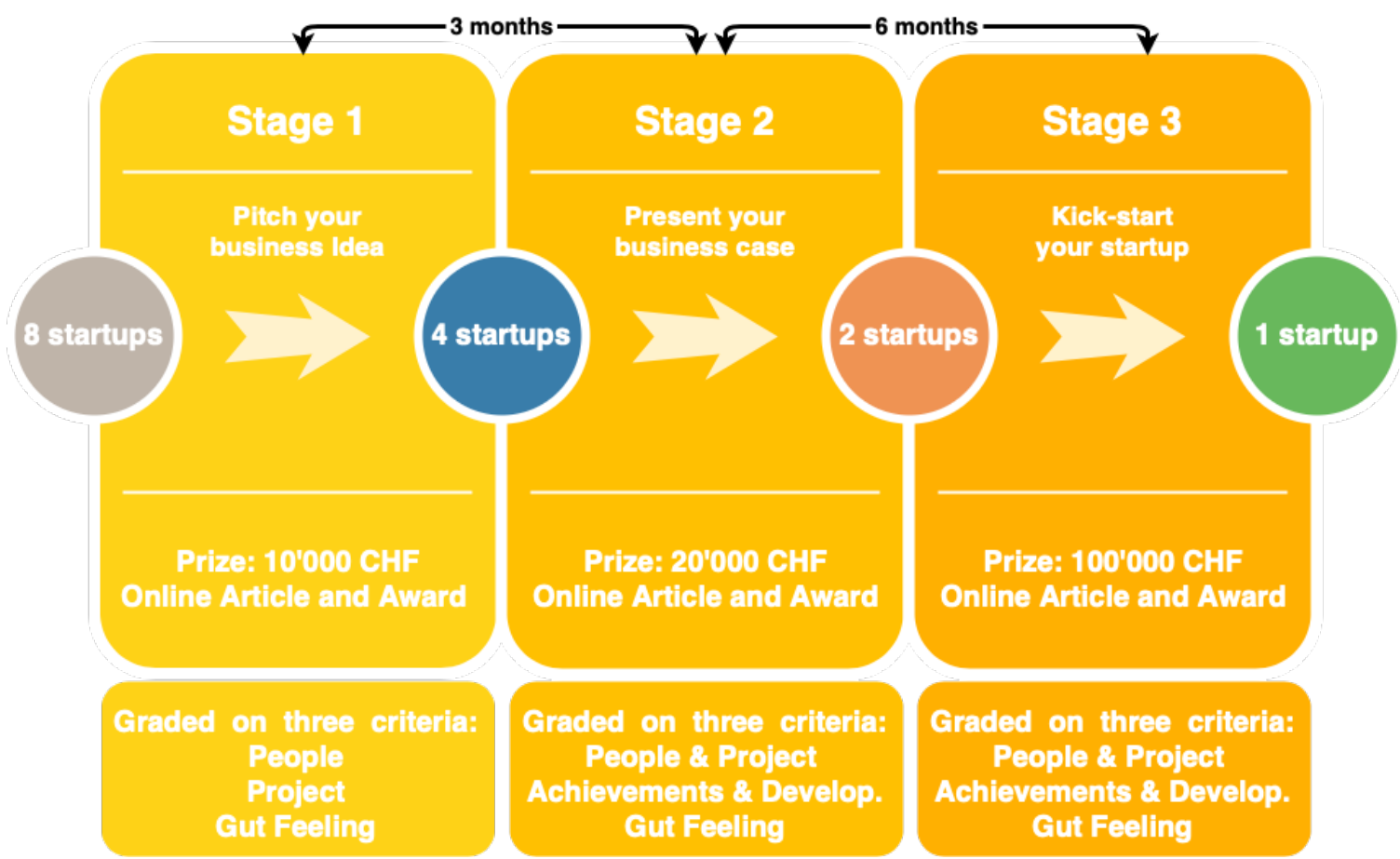

Source: EPFL 


\section{Appendix D: Principal component analysis using our eleven grades, in stage 1}

Table D.1: Eigenvalues of the components of our PCA, Stage 1

\begin{tabular}{lllll}
\hline Component & Eigenvalue & Difference & Proportion & Cumulative \\
\hline Comp 1 & 8.327 & 7.487 & 0.757 & 0.757 \\
Comp 2 & 0.841 & 0.397 & 0.076 & 0.834 \\
Comp 3 & 0.444 & 0.142 & 0.040 & 0.874 \\
Comp 4 & 0.301 & 0.046 & 0.027 & 0.901 \\
Comp 5 & 0.255 & 0.021 & 0.023 & 0.924 \\
Comp 6 & 0.235 & 0.060 & 0.021 & 0.946 \\
Comp 7 & 0.175 & 0.034 & 0.016 & 0.962 \\
Comp 8 & 0.141 & 0.029 & 0.013 & 0.974 \\
Comp 9 & 0.112 & 0.009 & 0.010 & 0.985 \\
Comp 10 & 0.103 & 0.036 & 0.009 & 0.994 \\
Comp 11 & 0.067 & 0.000 & 0.006 & 1.000 \\
\hline
\end{tabular}

Table D.2: Component loadings for the first four components, Stage 1

\begin{tabular}{llllll}
\hline Grades & Comp 1 & Comp 2 & Comp 3 & Comp 4 & Unexplained \\
\hline Visionary \& Leadership & 0.298 & 0.402 & 0.329 & 0.066 & 0.078 \\
Winning \& Communication & 0.269 & 0.587 & 0.299 & 0.019 & 0.069 \\
Credibility \& Expertise & 0.311 & -0.081 & -0.325 & 0.084 & 0.141 \\
Team \& Complementarity & 0.294 & 0.278 & -0.311 & 0.290 & 0.147 \\
Network \& References & 0.303 & -0.020 & -0.579 & 0.194 & 0.076 \\
Value proposition \& Opp. & 0.286 & -0.359 & 0.403 & 0.477 & 0.071 \\
Market \& Customers & 0.316 & -0.022 & -0.153 & -0.017 & 0.159 \\
USP \& IP & 0.283 & -0.456 & 0.121 & -0.114 & 0.150 \\
Business Model & 0.316 & -0.269 & 0.219 & -0.059 & 0.085 \\
Achievements \& Roadmap & 0.303 & 0.009 & -0.061 & -0.780 & 0.052 \\
Gut Feeling & 0.334 & -0.023 & 0.112 & -0.117 & 0.060 \\
\hline
\end{tabular}




\section{E Appendix E: Alternative identification strategies for main effect}

Table E.1: Errors-in-variables regression: Effect of winning stages 1, 2 and 3

\begin{tabular}{|c|c|c|c|}
\hline & \multicolumn{2}{|c|}{ Baseline } & \multirow{2}{*}{$\frac{\mathrm{EiV}}{(3)} \frac{}{\text { Survival } 2}$} \\
\hline & $\begin{array}{c}(1) \\
\text { Survival } 2\end{array}$ & $\begin{array}{c}(2) \\
\text { Survival } 2\end{array}$ & \\
\hline $\begin{array}{l}\text { First regression: Stage } 1 \\
\text { Wins Stage } 1\end{array}$ & $\begin{array}{l}0.220^{* * *} \\
(0.0683)\end{array}$ & $\begin{array}{l}0.354^{* * *} \\
(0.0456)\end{array}$ & $\begin{array}{l}0.257^{* * *} \\
(0.0811)\end{array}$ \\
\hline Standardized grade & $\begin{array}{l}0.119^{* * *} \\
(0.0353)\end{array}$ & $\begin{array}{c}0.0610^{* * *} \\
(0.0222)\end{array}$ & $\begin{array}{l}0.132^{* * *} \\
(0.0511)\end{array}$ \\
\hline $\begin{array}{l}\text { First regression: Stage } 2 \\
\text { Wins Stage } 2\end{array}$ & $\begin{array}{l}-0.0541 \\
(0.0666)\end{array}$ & $\begin{array}{l}0.101^{* *} \\
(0.0467)\end{array}$ & $\begin{array}{c}0.0608 \\
(0.0574)\end{array}$ \\
\hline Standardized grade & $\begin{array}{l}0.148^{* * *} \\
(0.0429)\end{array}$ & $\begin{array}{c}0.0427^{*} \\
(0.0224)\end{array}$ & $\begin{array}{l}0.0768^{*} \\
(0.0407)\end{array}$ \\
\hline $\begin{array}{l}\text { First regression: Stage } 3 \\
\text { Wins Stage } 3\end{array}$ & $\begin{array}{c}0.0477 \\
(0.0479)\end{array}$ & $\begin{array}{l}0.0782^{* *} \\
(0.0390)\end{array}$ & $\begin{array}{c}0.0569 \\
(0.0371)\end{array}$ \\
\hline Standardized grade & $\begin{array}{c}0.0578 \\
(0.0413)\end{array}$ & $\begin{array}{c}0.0226 \\
(0.0190)\end{array}$ & $\begin{array}{c}0.0407 \\
(0.0298)\end{array}$ \\
\hline Year FE & Yes & No & No \\
\hline Competition FE & Yes & No & No \\
\hline Industry FE & Yes & No & No \\
\hline University FE & Yes & No & No \\
\hline Observations stage 1 & 671 & 671 & 671 \\
\hline Observations stage 2 & 353 & 353 & 353 \\
\hline Observations stage 3 & 178 & 178 & 178 \\
\hline
\end{tabular}

Note: Table presents results of standard as well as error-in-variables regressions. Column (1) reports our baseline specification, Column (2) a standard regression without fixed effects which serves as a benchmark for Column (3), which shows our errors-in-variables regression with our grade variable having a reliability of 0.7 . Errors are clustered by competition round in columns (1). * ,**, and $* * *$ denote statistical significance at $10 \%, 5 \%$, and $1 \%$ levels, respectively. 
Table E.2: Control variables: Effect of winning stage 2

\begin{tabular}{|c|c|c|c|c|c|c|c|}
\hline & \multirow{2}{*}{ 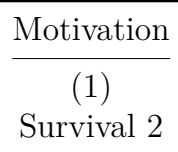 } & \multirow{2}{*}{ 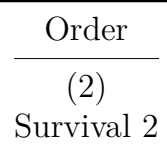 } & \multicolumn{3}{|c|}{ Other grade variables } & \multicolumn{2}{|c|}{ Funding } \\
\hline & & & $\begin{array}{c}(3) \\
\text { Survival } 2\end{array}$ & $\begin{array}{c}(4) \\
\text { Survival } 2\end{array}$ & $\begin{array}{c}(5) \\
\text { Funding } 2\end{array}$ & $\begin{array}{c}(6) \\
\text { Funding }\end{array}$ & $\begin{array}{c}(7) \\
\text { Rounds }\end{array}$ \\
\hline Wins Stage 2 & $\begin{array}{l}-0.0762 \\
(0.0643)\end{array}$ & $\begin{array}{l}-0.0503 \\
(0.0660)\end{array}$ & $\begin{array}{l}-0.0595 \\
(0.0673)\end{array}$ & $\begin{array}{l}-0.0628 \\
(0.0700)\end{array}$ & $\begin{array}{c}0.0236 \\
(0.0896)\end{array}$ & $\begin{array}{c}0.126 \\
(0.0873)\end{array}$ & $\begin{array}{l}0.456^{*} \\
(0.274)\end{array}$ \\
\hline Standardized grade & $\begin{array}{l}0.135^{* * *} \\
(0.0441)\end{array}$ & $\begin{array}{l}0.149^{* * *} \\
(0.0436)\end{array}$ & & & & $\begin{array}{c}0.106^{* *} \\
(0.0474)\end{array}$ & $\begin{array}{l}0.404^{* *} \\
(0.166)\end{array}$ \\
\hline Motivation & $\begin{array}{l}0.145^{* *} \\
(0.0711)\end{array}$ & & & & & & \\
\hline $\begin{array}{l}\text { Standardized average } \\
\text { grade }\end{array}$ & & & $\begin{array}{l}0.147^{* * *} \\
(0.0430)\end{array}$ & & & & \\
\hline $\begin{array}{l}\text { Standardized Gut } \\
\text { Feeling grade }\end{array}$ & & & & $\begin{array}{c}0.0231 \\
(0.0699)\end{array}$ & $\begin{array}{r}-0.0497 \\
(0.108)\end{array}$ & & \\
\hline $\begin{array}{l}\text { Standardized } \\
\text { Achievements grade }\end{array}$ & & & & $\begin{array}{l}0.00220 \\
(0.0678)\end{array}$ & $\begin{array}{l}0.00880 \\
(0.0884)\end{array}$ & & \\
\hline $\begin{array}{l}\text { Standardized Team \& } \\
\text { Project grade }\end{array}$ & & & & $\begin{array}{c}0.132 \\
(0.0867)\end{array}$ & $\begin{array}{c}0.174 \\
(0.114)\end{array}$ & & \\
\hline Order FE & No & Yes & No & No & No & No & No \\
\hline Year FE & Yes & Yes & Yes & Yes & Yes & Yes & Yes \\
\hline Competition FE & Yes & Yes & Yes & Yes & Yes & Yes & Yes \\
\hline University FE & Yes & Yes & Yes & Yes & Yes & Yes & Yes \\
\hline Industry FE & Yes & Yes & Yes & Yes & Yes & Yes & Yes \\
\hline Observations & 353 & 353 & 353 & 349 & 442 & 446 & 446 \\
\hline$R^{2}$ & 0.467 & 0.453 & 0.446 & 0.452 & 0.496 & 0.481 & 0.480 \\
\hline
\end{tabular}

Note: This table presents estimates of Equation (1) with additional controls, for stage 2. Column (1) controls for motivation, Column (2) for the order of passage during the competition, Columns (3) to (5) uses alternative grade variables. For the dependent variable, Columns (1) to (4) use the survival status two years after the competition as the dependent variable. Column (5) uses whether a startup received funding in the two years after the competition. Columns (6) and (7) introduce two new dependent variables, namely whether the startup secured financing after the competition, Funding, and the number of funding rounds secured, Rounds. The level of observation is a startup in a competition round. Errors are clustered by competition round. ${ }^{*}, *$, and ${ }^{* * *}$ denote statistical significance at $10 \%, 5 \%$, and $1 \%$ levels, respectively. 
Table E.3: Control variables: Effect of winning stage 3

\begin{tabular}{|c|c|c|c|c|c|c|c|}
\hline & \multirow{2}{*}{$\begin{array}{c}\frac{\text { Motivation }}{(1)} \\
\text { Survival } 2\end{array}$} & \multirow{2}{*}{ 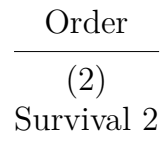 } & \multicolumn{3}{|c|}{ Other grade variables } & \multicolumn{2}{|c|}{ Funding } \\
\hline & & & $\begin{array}{c}(3) \\
\text { Survival } 2\end{array}$ & $\begin{array}{c}(4) \\
\text { Survival } 2\end{array}$ & $\begin{array}{c}(5) \\
\text { Funding } 2\end{array}$ & $\begin{array}{l}(6) \\
\text { Funding }\end{array}$ & $\begin{array}{c}(7) \\
\text { Rounds }\end{array}$ \\
\hline Wins Stage 3 & $\begin{array}{c}0.0574 \\
(0.0556)\end{array}$ & $\begin{array}{c}0.0392 \\
(0.0451)\end{array}$ & $\begin{array}{c}0.0319 \\
(0.0488)\end{array}$ & $\begin{array}{l}0.00321 \\
(0.0603)\end{array}$ & $\begin{array}{c}0.176 \\
(0.138)\end{array}$ & $\begin{array}{c}0.171 \\
(0.139)\end{array}$ & $\begin{array}{c}0.421 \\
(0.551)\end{array}$ \\
\hline Standardized grade & $\begin{array}{c}0.0580 \\
(0.0409)\end{array}$ & $\begin{array}{c}0.0644 \\
(0.0419)\end{array}$ & & & & $\begin{array}{c}0.0733 \\
(0.0807)\end{array}$ & $\begin{array}{c}0.377 \\
(0.284)\end{array}$ \\
\hline Motivation & $\begin{array}{l}-0.0352 \\
(0.0892)\end{array}$ & & & & & & \\
\hline $\begin{array}{l}\text { Standardized average } \\
\text { grade }\end{array}$ & & & $\begin{array}{c}0.0675 \\
(0.0434)\end{array}$ & & & & \\
\hline $\begin{array}{l}\text { Standardized Gut } \\
\text { Feeling grade }\end{array}$ & & & & $\begin{array}{c}0.171 \\
(0.141)\end{array}$ & $\begin{array}{r}-0.0297 \\
(0.141)\end{array}$ & & \\
\hline $\begin{array}{l}\text { Standardized } \\
\text { Achievements grade }\end{array}$ & & & & $\begin{array}{l}-0.0584 \\
(0.0683)\end{array}$ & $\begin{array}{c}0.0491 \\
(0.0964)\end{array}$ & & \\
\hline $\begin{array}{l}\text { Standardized Team \& } \\
\text { Project grade }\end{array}$ & & & & $\begin{array}{r}-0.0462 \\
(0.102)\end{array}$ & $\begin{array}{c}0.00723 \\
(0.145)\end{array}$ & & \\
\hline Order FE & No & Yes & No & No & No & No & No \\
\hline Year FE & Yes & Yes & Yes & Yes & Yes & Yes & Yes \\
\hline Competition FE & Yes & Yes & Yes & Yes & Yes & Yes & Yes \\
\hline University FE & Yes & Yes & Yes & Yes & Yes & Yes & Yes \\
\hline Industry FE & Yes & Yes & Yes & Yes & Yes & Yes & Yes \\
\hline Observations & 178 & 178 & 178 & 178 & 216 & 216 & 216 \\
\hline$R^{2}$ & 0.487 & 0.513 & 0.491 & 0.512 & 0.506 & 0.522 & 0.491 \\
\hline
\end{tabular}

Note: This table presents estimates of Equation (1) with additional controls, for stage 3. Column (1) controls for motivation, Column (2) for the order of passage during the competition, Columns (3) to (5) uses alternative grade variables. For the dependent variable, Columns (1) to (4) use the survival status two years after the competition as the dependent variable. Column (5) uses whether a startup received funding in the two years after the competition. Columns (6) and (7) introduce two new dependent variables, namely whether the startup secured financing after the competition, Funding, and the number of funding rounds secured, Rounds. The level of observation is a startup in a competition round. Errors are clustered by competition round. ${ }^{*}, *$, and ${ }^{* * *}$ denote statistical significance at $10 \%, 5 \%$, and $1 \%$ levels, respectively. 


\section{F Appendix F: Propensity Score Matching, balance across treatment and comparison groups}

Figure F.1: Propensity score balance across treatment and comparison groups, matching on grade, industry, university, gender and year, Stage 1
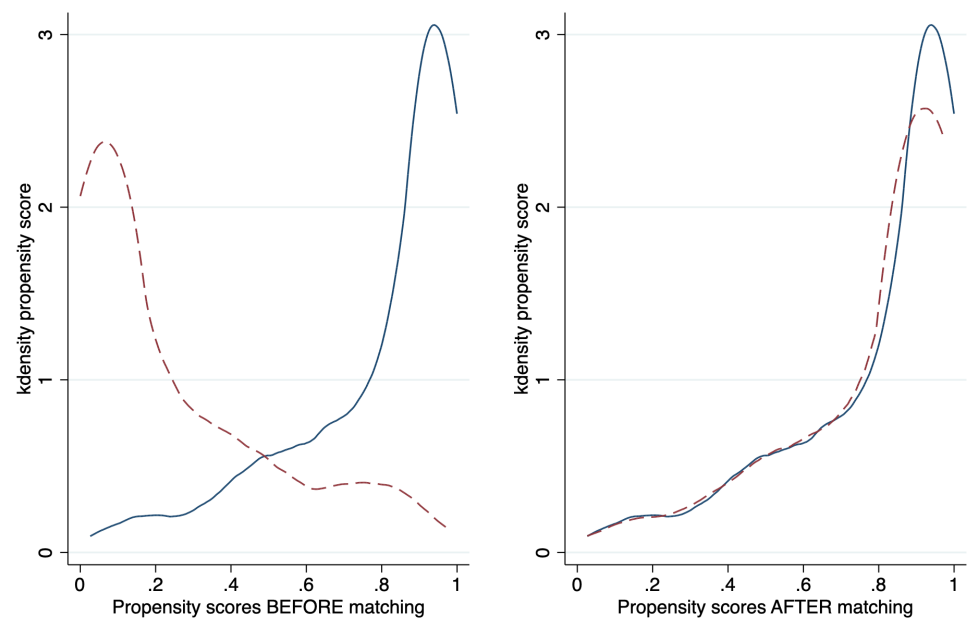

Startups that win stage 1

----- Startups that lose stage 1

Figure F.2: Propensity score balance across treatment and comparison groups, matching on grade, industry, university, gender and year, Stage 3
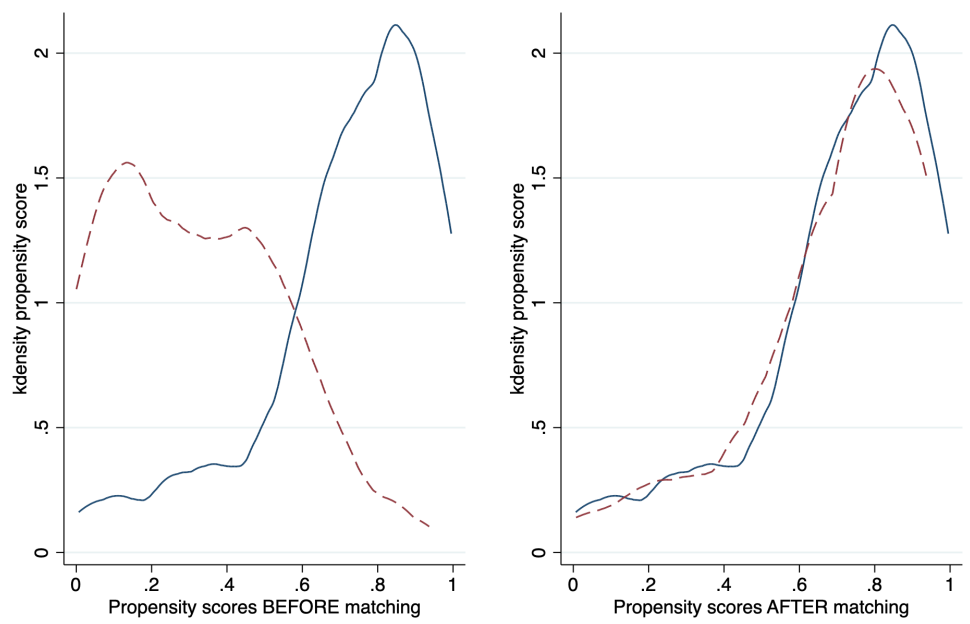

Startups that win stage 3

----- Startups that lose stage 3 


\section{G Appendix G: The non-linear effect of winning Ven- ture Kick's first stage}

Figure G.1: Marginal effect of winning stage 1 using a logistic regression

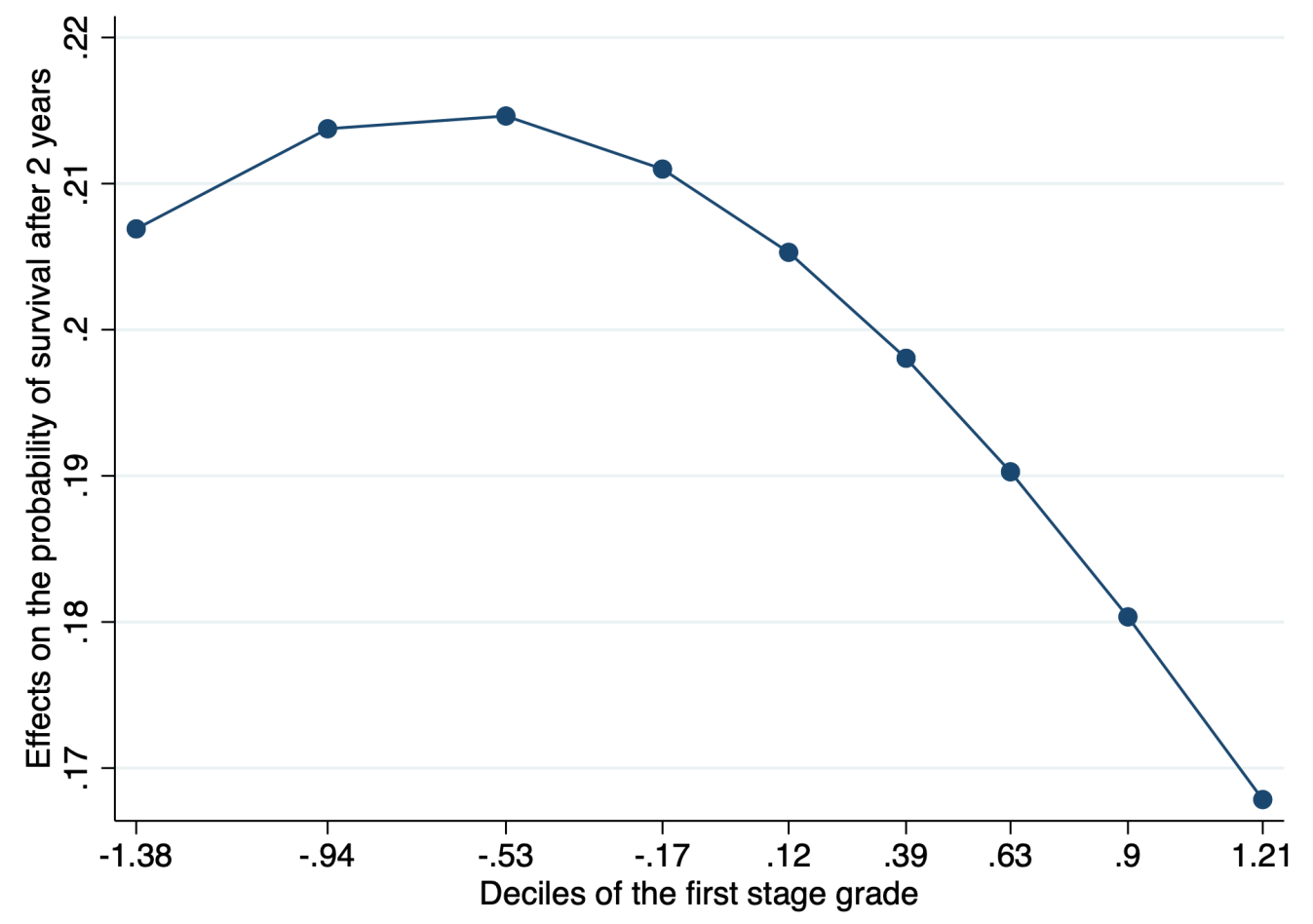

Note: This figure presents the effect of winning stage 1 on Survival 2 at the nine decile points of grades given in stage 1 using a logistic regression. 


\section{H Appendix H: Alternative identification strategies for heterogeneity}

Table H.1: RDD: Effect of winning stage 1 across sectors

\begin{tabular}{|c|c|c|c|c|}
\hline & \multicolumn{2}{|c|}{ RDD: Survival } & \multicolumn{2}{|c|}{ RDD: Funding } \\
\hline & $\begin{array}{c}(1) \\
\text { Survival } 2\end{array}$ & $\begin{array}{c}(2) \\
\text { Survival } 2\end{array}$ & $\begin{array}{c}(3) \\
\text { Rounds } 2\end{array}$ & $\begin{array}{c}(4) \\
\text { Funding } 2\end{array}$ \\
\hline Wins Stage 1 & $\begin{array}{c}0.118 \\
(0.0958)\end{array}$ & $\begin{array}{l}0.0989 \\
(0.115)\end{array}$ & $\begin{array}{l}0.0612 \\
(0.137)\end{array}$ & $\begin{array}{c}0.0335 \\
(0.0780)\end{array}$ \\
\hline Wins x Science & $\begin{array}{l}0.312^{* * *} \\
(0.0722)\end{array}$ & $\begin{array}{c}0.347^{* * *} \\
(0.101)\end{array}$ & $\begin{array}{c}0.384^{* * *} \\
(0.130)\end{array}$ & $\begin{array}{l}0.144^{* *} \\
(0.0636)\end{array}$ \\
\hline Losers' Rank & $\begin{array}{c}0.0336 \\
(0.0279)\end{array}$ & $\begin{array}{c}0.0283 \\
(0.0329)\end{array}$ & $\begin{array}{c}0.0156 \\
(0.0259)\end{array}$ & $\begin{array}{l}0.00867 \\
(0.0148)\end{array}$ \\
\hline Winners' Rank & $\begin{array}{c}0.0267 \\
(0.0221)\end{array}$ & $\begin{array}{c}0.0364 \\
(0.0264)\end{array}$ & $\begin{array}{c}0.0374 \\
(0.0334)\end{array}$ & $\begin{array}{c}0.0275 \\
(0.0172)\end{array}$ \\
\hline Science & $\begin{array}{l}-0.112^{* *} \\
(0.0542)\end{array}$ & $\begin{array}{l}-0.129^{* *} \\
(0.0640)\end{array}$ & $\begin{array}{l}-0.136^{* *} \\
(0.0658)\end{array}$ & $\begin{array}{c}-0.0701^{* *} \\
(0.0342)\end{array}$ \\
\hline Year FE & No & Yes & Yes & Yes \\
\hline Competition FE & No & Yes & Yes & Yes \\
\hline University FE & No & Yes & Yes & Yes \\
\hline $\begin{array}{l}\text { Observations } \\
R^{2}\end{array}$ & $\begin{array}{c}603 \\
0.224\end{array}$ & $\begin{array}{c}603 \\
0.372\end{array}$ & $\begin{array}{c}804 \\
0.320\end{array}$ & $\begin{array}{c}804 \\
0.305\end{array}$ \\
\hline
\end{tabular}

Note: This table presents results of linear regressions using regression discontinuity designs (RDDs). Columns (1) and (2) display parametric RDDs with Wins Stage 1 as the effect of winning for ICT startups. Columns (3) and (4) use the same approach for funding. The level of observation is a startup in a competition round. Errors are clustered by competition round. *, **, and *** denote statistical significance at $10 \%, 5 \%$, and $1 \%$ levels, respectively. 
Table H.2: PSM: Average treatment effect of winning stage 1, 2 and 3

\begin{tabular}{lccccc}
\hline & \multicolumn{2}{c}{ Science } & \multicolumn{2}{c}{ Internet and Software } \\
& $\begin{array}{c}(1) \\
\text { Survival 2 }\end{array}$ & $\begin{array}{c}(2) \\
\text { Rounds 2 }\end{array}$ & $\begin{array}{c}(3) \\
\text { Survival 2 }\end{array}$ & $\begin{array}{c}(4) \\
\text { Rounds 2 }\end{array}$ \\
\hline First regression: Stage 1 & & & & \\
Wins Stage 1 & $0.395^{* * *}$ & $0.410^{* * *}$ & & 0.131 & -0.0307 \\
& $(0.132)$ & $(0.135)$ & & $(0.185)$ & $(0.127)$ \\
\hline Second regression: Stage 2 & & & & \\
Wins Stage 2 & $0.105^{*}$ & $0.346^{* *}$ & & -0.0970 & -0.0675 \\
& $(0.0632)$ & $(0.170)$ & & $(0.126)$ & $(0.147)$ \\
\hline Third regression: Stage 3 & & & & \\
Wins Stage 3 & 0.0153 & 0.278 & & $0.255^{* * *}$ & 0.407 \\
& $(0.0130)$ & $(0.220)$ & & $(0.0730)$ & $(0.297)$ \\
\hline Observations stage 1 & 365 & 502 & & 306 & 391 \\
Observations stage 2 & 219 & 283 & & 134 & 163 \\
Observations stage 3 & 131 & 162 & & 47 & 54 \\
\hline
\end{tabular}

Note: Table presents the average treatment effect from a propensity score matching for stages 1, 2 and 3. The level of observation is a startup in a competition round. Errors are clustered by competition round. $* * *$, and ${ }^{* * *}$ denote statistical significance at $10 \%, 5 \%$, and $1 \%$ levels, respectively. 